Int. J. Dev. Biol. 58: 501-511 (2014)

doi: $10.1387 / \mathrm{ijdb} .140121 \mathrm{ad}$

\title{
A conserved set of maternal genes? Insights from a molluscan transcriptome
}

\author{
M. MAUREEN LIU1,2, JOHN W. DAVEY ${ }^{3,4}$, DANIEL J. JACKSON ${ }^{5}$, MARK L. BLAXTER ${ }^{3,6}$ and ANGUS DAVISON ${ }^{*, 1}$ \\ ${ }^{1}$ School of Life Sciences, University of Nottingham, University Park, Nottingham, UK, ${ }^{2}$ Department of Plant Sciences, \\ University of Cambridge, Downing Street, Cambridge, UK, ${ }^{3}$ Institute of Evolutionary Biology, University of Edinburgh, \\ Edinburgh, UK, ${ }^{4}$ Department of Zoology, University of Cambridge, Downing Street, Cambridge, UK, ${ }^{5}$ Courant Research \\ Centre for Geobiology, University of Göttingen, Göttingen, Germany and ${ }^{6}$ Edinburgh Genomics, \\ School of Biological Sciences, University of Edinburgh, Edinburgh, UK
}

\begin{abstract}
The early animal embryo is entirely reliant on maternal gene products for a 'jump-start' that transforms a transcriptionally inactive embryo into a fully functioning zygote. Despite extensive work on model species, it has not been possible to perform a comprehensive comparison of maternally-provisioned transcripts across the Bilateria because of the absence of a suitable dataset from the Lophotrochozoa. As part of an ongoing effort to identify the maternal gene that determines left-right asymmetry in snails, we have generated transcriptome data from 1 to 2-cell and 32-cell pond snail (Lymnaea stagnalis) embryos. Here, we compare these data to maternal transcript datasets from other bilaterian metazoan groups, including representatives of the Ecydysozoa and Deuterostomia. We found that between 5 and $10 \%$ of all $L$. stagnalis maternal transcripts $(-300-400$ genes) are also present in the equivalent arthropod (Drosophila melanogaster), nematode (Caenorhabditis elegans), urochordate (Ciona intestinalis) and chordate (Homo sapiens, Mus musculus, Danio rerio) datasets. While the majority of these conserved maternal transcripts ("COMATs") have housekeeping gene functions, they are a non-random subset of all housekeeping genes, with an overrepresentation of functions associated with nucleotide binding, protein degradation and activities associated with the cell cycle. We conclude that a conserved set of maternal transcripts and their associated functions may be a necessary starting point of early development in the Bilateria. For the wider community interested in discovering conservation of gene expression in early bilaterian development, the list of putative COMATs may be useful resource.
\end{abstract}

KEY WORDS: maternal to zygotic transition, mollusk, MBT, MZT, Spiralia

\section{Introduction}

Cell division requires that genome replication and assortment are achieved while cellular function is maintained. In somatic cells, there is continuity of cytoplasm from mother to daughter, so that new nuclei take up the reins of cellular control as transcription of their genomes is resumed after division. In contrast, in the formation of a new organism the early zygote has to perform a similar feat of taking control of a new cell, but the task is made more complex because the gametic pronuclei must be reprogrammed and coordinated before transcription initiation. In animal embryos the zygotic cytoplasm, provisioned by the mother, has been found to contain all the machinery necessary to drive the first stages of embryonic development. This maternal provisioning has been demonstrated through the blocking of transcription from the zygotic genome (Baroux et al., 2008). In transcriptionally-blocked

Abbreviations used in this paper: bp, base pair; COMAT, conserved maternal transcript; GO, gene ontology; MBT, midblastula transition; MZT, maternal-zygotic transition.

\footnotetext{
*Address correspondence to: Angus Davison. School of Life Sciences, University of Nottingham, University Park, Nottingham, UK.

E-mail: angus.davison@nottingham.ac.uk - web: http://angusdavison.org
}

Supplementary Material (one figure and 4 tables) for this paper is available at: http://dx.doi.org/10.1387/ijdb.140121ad

Accepted: 18 September 2014.

ISSN: Online 1696-3547, Print 0214-6282

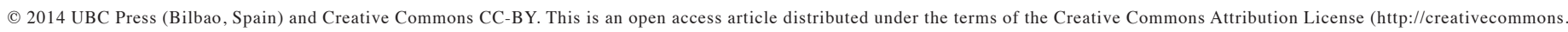

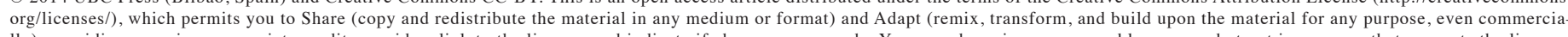

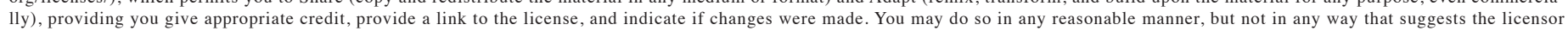
endorses you or your use.

Printed in Spain 
embryos, maternal products are often sufficient to drive the first rounds of cell division, and even the first phases of differentiation (Baroux et al., 2008).

The switch between maternal and zygotic control is called the maternal-zygotic transition (MZT), or the midblastula transition (MBT), and spans the period from fertilisation to the point where maternally provisioned factors are no longer sufficient to deliver normal development (Baroux et al., 2008, Stitzel and Seydoux, 2007, Tadros and Lipshitz, 2009). The MZT is associated with the activation of the zygotic genome. In animal species where finescale analyses have been performed, zygotic gene activation has been modelled as two phases (Baroux et al., 2008, Tadros and Lipshitz, 2009). An early phase, involving a few loci, is associated with degradation of maternal proteins and mRNAs, while the second phase is much more extensive and includes genes involved in a wide range of biological processes (Schier, 2007, Tadros and Lipshitz, 2009). Initial, albeit limited, zygotic genome activation has been identified as early as the fertilised zygote (in the paternal pronuclei of mouse, sea urchin and the nematode Ascaris suum), and as late as the 256-cell embryo stage (in Xenopus) (Baroux et al., 2008, Tadros and Lipshitz, 2009, Wang et al., 2013).

Experimental evidence indicates that the MZT is tightly regulated, and includes the birth of zygotic RNAs and the death of maternal RNAs (Schier, 2007, Stitzel and Seydoux, 2007, Tadros and Lipshitz, 2009), taking place at multiple levels and in a controlled and managed manner. Thus, while many embryos are able to transcribe experimentally introduced DNA, the early embryonic genome is maintained in a state that is incompatible with transcription. Changes in chromatin structure, combined with a dilution of factors such as transcriptional repressors by cell division, allow for the initiation of zygotic transcription. Nonetheless, despite the complexity, it has been suggested that the MZT can be simplified into two interrelated processes: the first whereby a subset of maternal mRNAs and proteins is eliminated, and the second whereby zygotic transcription is initiated (Schier, 2007, Tadros and Lipshitz, 2009).

In zebrafish, maternally-provisioned products from just three genes, Nanog, Pou5f1 and SoxB1 (known for their roles in embryonic stem cell fate regulation), are sufficient to initiate the zygotic developmental program and to induce clearance of the maternal program by activating the expression of a microRNA (Lee et al.,

Fig. 1. Enrichment of Gene Ontology terms in the conserved maternal transcript (COMAT) subset. Highest level GO terms that show the greatest enrichment in COMAT compared with the L. stagnalis 1 to 2-cell transcriptome. Only those comparisons with $P<1 E-5$ are shown. Black shading: percentage of each type in COMAT. Grey shading: percentage of each type in the 1 to 2-cell transcriptome.
2013, Leichsenring et al., 2013). In Xenopus, increasing nuclear to cytoplasmic ratio is believed to be the controlling element in the switch, with just four factors regulating multiple events during the transition (Collart et al., 2013). However, the generality of these findings remains unknown. Furthermore, while the regulation of RNA transcription (gene expression) has received considerable attention (primarily due to the advances in nucleic acid sequencing technologies), protein expression and turnover rates remain relatively under-studied (Stitzel and Seydoux, 2007). Our knowledge of maternal-to-zygotic transcription phenomena is also largely restricted to the dominant model animal species, with relatively few experimental studies existing for other metazoans.

Although there has been a recent upsurge in interest in the maternal control of embryonic development, especially the MZT (Benoit et al., 2009, De Renzis et al., 2007, Lee et al., 2013, Leichsenring et al., 2013, Tadros and Lipshitz, 2009), the study of maternal factors has played an important part in the history of embryology and development, particularly in the model animal taxa Drosophila melanogaster (phylum Arthropoda from superphylum Ecdysozoa), Caenorhabditis elegans (Nematoda, Ecdysozoa), Strongylocentrotus purpuratus (Echinodermata, Deuterostomia), Mus musculus, Homo sapiens and Danio rerio (Chordata, Deuterostomia) (Gilbert, 2006). Missing from this roster of models are representatives of "the" superphylum Lophotrochozoa, a morphologically diverse group that includes the Mollusca and Annelida. Two annelid models, Platynereis dumeriliiand Capitella telata, are becoming well established (Dill and Seaver, 2008, Giani et al., 2011, Hui et al., 2009), but model molluscs have been developed for their potential to answer particular questions (e.g. asymmetric distribution of patterning molecules during development; Lambert and Nagy, 2002), or their association with a particular disease (e.g. schistosome transmitting Biomphalaria; Knight et al., 2011).

As part of an ongoing effort to identify the maternal gene that determines left-right asymmetry in molluscs (Harada et al., 2004, Kuroda et al., 2009, Liu et al., 2013), we are developing Lymnaea stagnalis pond snails as a model because they are one of the few groups that exhibit genetically-tractable, natural variation in their left-right asymmetry, or chirality, and so are ideal systems in which to understand why chirality is normally invariant, yet also pathological when it does vary (Schilthuizen and Davison, 2005). In generating a maternal transcriptomic resource for this species (the chirality-determining gene is maternally expressed; Boycott and Diver, 1923, Sturtevant, 1923), we were surprised to discover that while there are general studies on the composition and regulation of maternal expression (Shen-Orr et al., 2010), there has been no comprehensive description of shared bilaterian maternal genes.

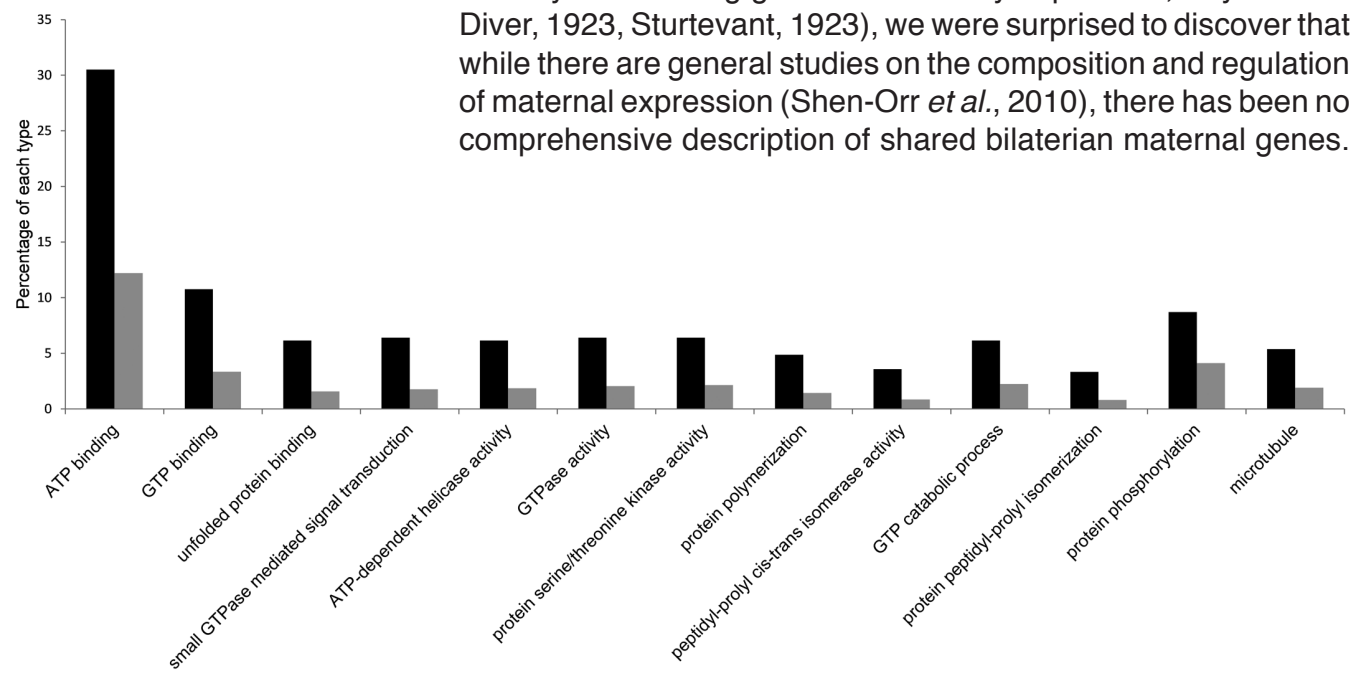


One reason may be that no maternal gene resource exists for the Lophotrochozoa, Spiralia or Mollusca. Instead, previous work has described early developmental transcription in the molluscs Ilyanassasp. (Lambert et al., 2010) and Crepidula fornicata (Henry et al., 2010), but using combined developmental stage libraries. Here we compare a new 1 to 2 -cell $L$. stagnalis transcriptome (presumed maternal) to maternal transcriptomes from selected ecdysozoan and deuterostome species to identify conserved maternally provisioned genes across the Bilateria.

\section{Results}

\section{L. stagnalis embryonic transcriptome sequencing and as- sembly}

Roche 454 sequencing of the two $L$. stagnalis libraries (1 to 2-cell and $\sim 32$-cell) generated 192,758 and 218,893 reads respectively, of which 163,004 and 192,552 were 150 bases or longer. The 1 to 2 -cell assembly generated more contigs than the $\sim 32$-cell assembly, despite having fewer sequences (Table 2). A GC content of $36 \%$ for both libraries was approximately the same as previously reported for L. stagnalis (Adema et al., 2006, Liu et al., 2013). Merging the two assemblies produced by Newbler and MIRA resulted in fewer, longer contigs. The 1 to 2 -cell library generated 11,212 contigs, and the $\sim 32$ cell library 9,497 contigs.

\section{Comparison between maternal transcriptomes}

We compared the two developmental transcriptomes of $L$. stagnalis to each other and to six published maternal transcriptomes of roughly comparable depth derived from four deuterostomes and two ecdysozoans (Table 3; Aanes et al., 2011, Azumi et al., 2007, Baugh et al., 2003, De Renzis et al., 2007, Evsikov et al., 2006, Grondahl et al., 2010). For M. musculus and C. elegans, maternal-only transcripts (present in the oocyte or egg but not in developing embryos) and maternal-zygotic transcripts (found in both oocyte or egg, and after zygotic transcription has started) have been defined. For the mouse, 2,834 genes were maternalonly and 1,796 maternal-zygotic, while for $C$. elegans 2,794 were maternal-only and 2,285 maternal-zygotic (Baugh et al., 2003, Evsikov et al., 2006).

By reciprocal tBLASTx analyses, we identified putatively orthologous genes present in each of the seven species. About one quarter of each of the other maternal transcriptomes, between 900 and 1,900 genes, overlapped with the maternal transcriptome of the pond snail, L. stagnalis (Table 4). Surprisingly, 481 of the $L$. stagnalis genes had putative orthologues in all seven taxa (Supplementary Table 1). These 481 orthologues in fact probably represent 439 or fewer distinct genes, as BLASTx analyses revealed that some matched the same sequence in the NCBI nr protein database. This result implies that $5-10 \%$ of the maternal transcriptome is conserved and shared across all of the representative taxa $(H$. sapiens $6.1 \%$, M. musculus $9.9 \%$, D. rerio $10.6 \%$, C. intestinalis $11.4 \%$, D. melanogaster $7.0 \%$, C. elegans $9.0 \%$ ). We refer to this conserved set as the "conserved maternal transcriptome" (COMAT).

We compared the L. stagnalis 1 to 2 -cell transcriptome to maternal-only transcripts and maternal-zygotic transcripts from M. musculus and C. elegans (Baugh et al., 2003, Evsikov et al., 2006) using tBLASTx. The M. musculus maternal-only data set matched 1069 L. stagnalis transcripts, whereas the $M$. musculus maternal-zygotic data set matched 884 L. stagnalis transcripts. Of the 481 COMATs from $L$. stagnalis, 219 were found in the M. musculus maternal-only data set and 261 in the M. musculus maternal-zygotic data set, indicating a relative over-representation of

ig. 2. Visualisation of maternal gene product spatial distribution in uncleaved zygotes of Lymnaea stagnalis by whole mount in situ hybridisation. Eight maternal gene products were visualised in uncleaved zygotes relative to a negative control ( $\beta$-tubulin). (A) $\beta$-tubulin is not detectable in uncleaved zygotes. A polar body is indicated by the horizontal arrow. (B) $\beta$-tubulin is clearly expressed in ciliated cells of older veliger larvae. (C) contig_2724: ATP-dependent RNA helicase dhx8. (D) contig_453: heat shock 70 kda protein cognate 4. (E) contig_7974: ADP-ribosylation factor 4. (F) contig_9053: proteasome alpha 6 subunit. (G) contig_579: ergic and golgi 2. (H) contig_9016: eukaryotic translation initiation factor 3 subunit i. (I) contig_8075: eukaryotic translation elongation factor. (J) contig_8318: 78 kda glucose-regulated protein. 
TABLE 1

PRIMER SEQUENCES USED TO ISOLATE GENE FRAGMENTS FOR RIBOPROBE SYNTHESES

Gene

beta-tubulin

c2724 ATP-dependent RNA helicase

c453 heat shock 70 kda protein

c7974 ADP-ribosylation factor 4

c9053 proteasome alpha 6 subunit

c579 ergic and golgi 2

c9016 eukaryotic translation initiation factor 3 subunit i

c8075 eukaryotic translation elongation factor

c8318 78 kda glucose-regulated protein
Forward primer (5' to $\left.3^{\prime}\right)$

TGTGGAATGGATCCCCAACAATGTCA

GCAGCGGTTTCTTCCGCAATG

CCACTGCTGCAGCCATTGCCTA

CAAGGTGCAACTGCCACGCAAG

CGCGCTCGCTATGAGGCAGCTA

CGTCTGCTACAGGTGGCGGTTTG

TGGTGCTGTTTGGTGCATTGATTG

TACTGCGCCAAGCCATTGGTGA

CGCAAAACCAGCGACATATAAGCA
Reverse primer (5' to $\left.3^{\prime}\right)$ TCACTCAGGAGCTTTGATACGGCTTG TTTTTCTCTCСTCTTTACTGCTG CTGAATGAGCACACCGGGCTGA AAATCCCACCACCACCCCCAAC TCATGGTATCAGCAACACCCACA TCCGTGGTTGATTGGCCGGTTA AGCGGGCATCAAATTTGCCAAC CTGAAGCAGGGCATCACCAGCA TGGCTGCAGCAGTTGGCTCATT

TABLE 2

\section{ASSEMBLY OF THE LYMNAEA STAGNALIS EMBRYO TRANSCRIPTOMES}

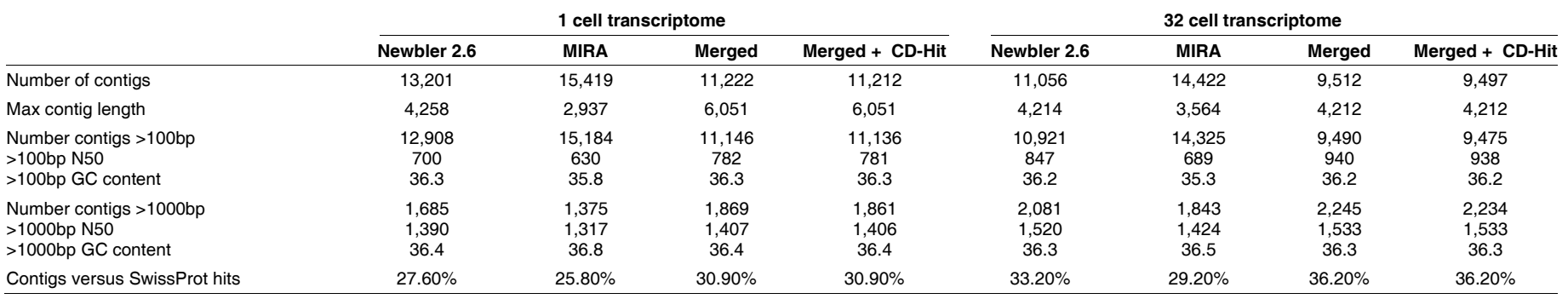

TABLE 3

\section{MATERNAL TRANSCRIPTOME DATASETS USED IN THIS STUDY}

\begin{tabular}{|c|c|c|c|c|}
\hline Taxonomic group / Species & Common name & Number of maternal genes & Method & Source \\
\hline \multicolumn{5}{|l|}{ Deuterostomia } \\
\hline Homo sapiens & human & 7,470 & Array analysis of metaphase II oocytes & Grøndahl et al. 2010 \\
\hline Mus musculus & mouse & $4,643^{*}$ & Sanger sequencing of oocyte cDNA library & Evsikov et al. 2006 \\
\hline Danio rerio & zebrafish & $4,375^{\star}$ & ABI Solid cDNA sequences of oocyte and early embryo & Aanes et al. 2011 \\
\hline Ciona intestinalis & Ciona / sea squirt & 4,041 & Array analysis of early embryo & Azumi et al. 2007 \\
\hline \multicolumn{5}{|l|}{ Ecdysozoa } \\
\hline Drosophila melanogaster & Drosophila / fly & $6,582^{\#}$ & Array analysis of early embryo & De Renzis et al. 2007 \\
\hline Caenorhabditis elegans & C. elegans / worm & $5,081^{*}$ & Array analysis of early embryo & Baugh et al. 2003 \\
\hline \multicolumn{5}{|l|}{ Lopphotrochozoa } \\
\hline Lymnaea stagnalis & snail & 11,212 & 454 sequencing of cDNA library from 1 cell embryo & This study \\
\hline
\end{tabular}

* more sequences listed in paper, but not all retrievable or present in database (mouse $\sim 5,400$; worm 6,042; zebrafish 4,465)

" fewer sequences listed in paper compared with database $(6,485)$

TABLE 4

\section{COMPARISON BETWEEN MATERNAL TRANSCRIPTOMES}

\begin{tabular}{|c|c|c|c|c|c|c|c|c|c|}
\hline Species & $\begin{array}{c}\text { Maternal } \\
\text { transcriptome }\end{array}$ & $\begin{array}{l}\text { Number with orthologues in } \\
\text { Lymnaea stagnalis transcriptome }\end{array}$ & $\%$ & $\begin{array}{l}\text { Unique } \\
\text { hits }\end{array}$ & $\%$ & $\begin{array}{l}\text { Reciprocal } \\
\text { hits }\end{array}$ & $\%$ & $\begin{array}{l}\text { Unique } \\
\text { reciprocal hits }\end{array}$ & $\%$ \\
\hline Homo sapiens & 7,470 & 2,394 & $32 \%$ & 1,852 & $25 \%$ & 2,698 & $36 \%$ & 1,768 & $24 \%$ \\
\hline Mus musculus & 4,643 & 1,954 & $42 \%$ & 1,442 & $31 \%$ & 2,013 & $43 \%$ & 1,361 & $29 \%$ \\
\hline Danio rerio & 4,375 & 1,913 & $44 \%$ & 1,452 & $33 \%$ & 1,985 & $45 \%$ & 1,328 & $30 \%$ \\
\hline Ciona intestinalis & 4,041 & 1,360 & $34 \%$ & 954 & $24 \%$ & 1,110 & $27 \%$ & 936 & $23 \%$ \\
\hline Drosophila melanogaster & 6,582 & 2,501 & $38 \%$ & 1,980 & $30 \%$ & 2,903 & $44 \%$ & 1,900 & $29 \%$ \\
\hline Caenorhabditis elegans & 5,081 & 1,662 & $33 \%$ & 1,220 & $24 \%$ & 1,628 & $32 \%$ & 1,181 & $23 \%$ \\
\hline
\end{tabular}


maternal-zygotic transcripts that are conserved between chordate and mollusc, compared with maternal-only (Fisher's exact test, 2,834:1,796 maternal-only:maternal-zygotic $M$. musculus versus 1,069:884 maternal-only:maternal-zygotic $L$. stagnalis, $P$ $<0.0001$ ), especially when considering COMATs (Fisher's exact test, $2,834: 1,796$ versus $219: 261, P<0.0001)$. A similar result was found in comparisons between $L$. stagnalis and $C$. elegans (Fisher's exact test, 2794:2285 versus 733:929 or 222:259, $P<$ $0.0001, P<0.0002)$. Similar comparisons were also made for maternal transcripts identified as being actively degraded or not degraded in the early embryo (Baugh et al., 2003, Evsikov et al., 2006), but no differences were found.

\section{Gene ontology analyses}

About one-third (31\% of the 1 to 2 -cell and and $36 \%$ of the $\sim 32-$ cell) L. stagnalis transcripts $(\sim 3,400$ genes) had significant BLASTx matches in the SwissProt database (Table 2). Blast2GO was used to functionally annotate both $L$. stagnalis transcriptomes. Of the 11,212 1 to 2-cell contigs, 4,311 (38\%) had a significant BLASTx match, and 3,481 (31\%) were assigned GO identifiers. Similarly, of 9,497 32-cell contigs, 4,255 (45\%) had a significant BLASTx match, and 3,425 (36\%) were assigned GO identifiers. For the COMAT subset, all but one of the 481 sequences had a significant BLASTx match, and 435 (90\%) were assigned GO identifiers (Supplementary Table 1).

The distribution of GO annotations into functional categories revealed no obvious qualitative differences between the 1 to 2 -cell and $\sim 32$ cell L. stagnalistranscriptomes (Supplementary Figure 1). A Fisher's exact test, with multiple correction for false discovery rate, confirmed that no functional categories were significantly under or overrepresented between the two libraries. In comparison, the COMAT subset was enriched for many functional categories compared with the complete L. stagnalis 1 to 2 -cell transcriptome

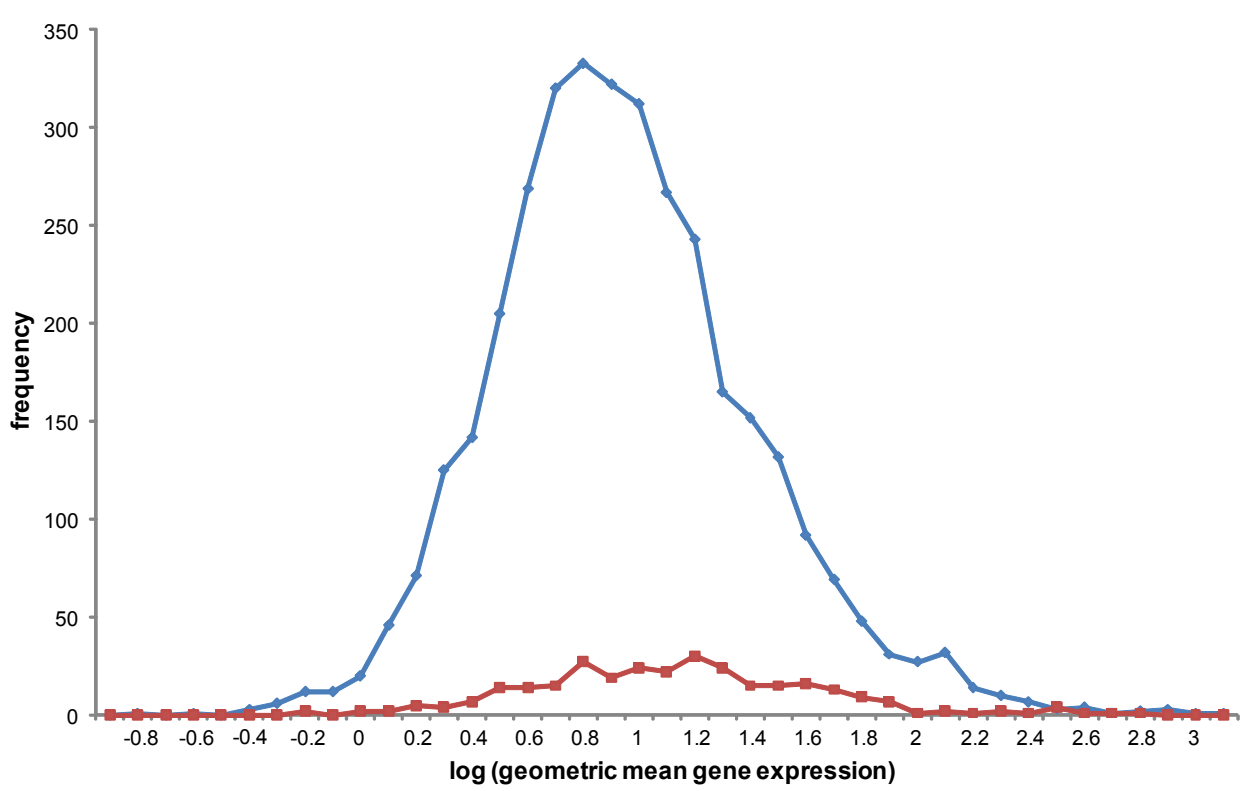

Fig. 3. Frequency histogram of relative gene expression for human housekeeping genes. Conserved maternal transcripts (COMATs, red line) tend to have a higher gene expression (measured reads per kb per million mapped reads, RPKM) than non-COMATs (blue). However, COMATs still represent several orders of magnitude of gene expression. Gene expression data from Eisenberg \& Levanon (2013).
(Fig. 1; Table 5; Supplementary Table 2). In particular, GO terms associated with nucleotide metabolism and binding in general were overrepresented in the COMAT subset (Figure 1; Table 5; Supplementary Table 2). The maternal expression of a selected set of the COMAT genes was validated in one-cell zygotes using in situ methods (Fig. 2).

\section{Comparison with human housekeeping genes}

The COMAT subset was compared to 3802 well-characterised human housekeeping genes (Eisenberg and Levanon, 2013). All but 38 of the 481 COMAT transcripts had a significant match to this set $(92 \%)$, indicating that the majority are housekeeping in function, at least in humans. In comparison, of the 4,311 L. stagnalis 1 to 2-cell transcripts that had a significant BLASTx match in the $\mathrm{NCBI}$ nr protein database, only $2,165(50 \%)$ also had matches to the human housekeeping gene dataset. The conserved maternal gene dataset is therefore highly enriched for putative housekeeping genes (Fisher's exact test, 2156:4311 versus 443:481, $P<0.0001$ ).

We wished to understand if a particular subset of housekeeping genes are over-represented in the COMAT subset, or whether the genes are a random subset of all housekeeping genes. We therefore compared the GO annotations of the 3,802 human housekeeping genes against the subset of 300 human housekeeping genes (Table 6) that were found in the COMAT (a proportion of the COMATs hit the same human gene, hence fewer genes than expected). Similar GO annotations were enriched in this selected pairwise comparison compared with the COMAT as a whole (Supplementary Tables 3 and 4). At the highest level, the same first seven Molecular Functions were found in both $H$. sapiens housekeeping versus $H$. sapiens COMAT, and $L$. stagnalis 1 to 2-cell transcriptome versus $L$. stagnalis COMAT comparisons, with $P<5 E^{-8}$ (Supplementary Table 4; ATP binding, GTPase activity, unfolded protein binding, protein serine/threonine kinase activity, GTP binding, threonine-type endopeptidase activity, and ATP-dependent RNA helicase activity). Similarly, the first seven terms relating to Biological Process were also found $\left(P<5 \mathrm{E}^{-8}\right.$; anaphase-promoting complex-dependent proteasomal ubiquitin-dependent protein catabolic process, protein polyubiquitination, negative regulation of ubiquitin-protein ligase activity involved in mitotic cell cycle, DNA damage response, signal transduction by p53 class mediator resulting in cell cycle arrest, positive regulation of ubiquitinprotein ligase activity involved in mitotic cell cycle, antigen processing and presentation of exogenous peptide antigen via MHC class I, and TAP-dependent, GTP catabolic process). Thus, the overall conclusion is that the COMAT generally consists of housekeeping genes, but is particularly enriched for a particular subset, including those involved in nucleotide binding functions, protein degradation and activities associated with the cell cycle.

A final concern was that the COMATs 
are simply conserved genes that tend to be highly expressed, and so are more likely to be detected in non-exhaustive sequencing experiments. We therefore used the expression data of Eisenberg \& Levanon (2013) to compare the read depth of these two types of gene (COMATS and non-COMATS) in human tissues. Overall, COMATs tend to be more highly expressed, but they represent a set of genes that have a large range in their quantitative gene expression (Figure 3). Thus, while the mean gene expression in the conserved data set is higher (COMAT mean log geometric gene expression $=1.08$, S.E. 0.03; non-COMAT mean $=0.90$, S.E. $0.008 ; P<0.001$ ), the individual variation is considerable in both datasets (S.D. 0.51 and 0.47 respectively). Thus, a lack of depth in sequencing experiments cannot wholly explain the existence of COMATs.

\section{Discussion}

Much excitement has been caused by the discovery that the evolution of gene expression patterns seems to underpin the morphological hourglass pattern of both plants and animals (Kalinka et al., 2010, Meyerowitz, 2002, Quint et al., 2012). Thus, the long-standing observation that vertebrate morphology is at its most

TABLE 5

HIGHEST LEVEL GENE ONTOLOGY TERMS ENRICHED IN THE CONSERVED MATERNAL DATASET

\begin{tabular}{|c|c|c|c|c|c|c|c|c|c|}
\hline GO-ID & Term$^{*}$ & Category & FDR & $\begin{array}{c}\text { P-Value } \\
\text { after FDR }\end{array}$ & $\begin{array}{l}\text { Number in } \\
\text { test group }\end{array}$ & $\begin{array}{l}\text { Number in } \\
\text { cell reference }\end{array}$ & $\begin{array}{l}\text { Number in } \\
\text { reference total a }\end{array}$ & $\begin{array}{c}\text { Number not } \\
\text { annotated in test }\end{array}$ & $\begin{array}{l}\text { Number not } \\
\text { annotated } \\
\text { reference }\end{array}$ \\
\hline$\overline{\mathrm{GO}} 00005524$ & ATP binding & $\mathrm{F}$ & $2.83 \mathrm{E}-33$ & $5.84 \mathrm{E}-36$ & 119 & 136 & 255 & 271 & 1953 \\
\hline GO:0005525 & GTP binding & $\mathrm{F}$ & $2.62 \mathrm{E}-15$ & $1.08 \mathrm{E}-17$ & 42 & 28 & 70 & 348 & 2061 \\
\hline GO:0051082 & unfolded protein binding & $\mathrm{F}$ & $5.10 \mathrm{E}-11$ & $2.75 \mathrm{E}-13$ & 24 & 9 & 33 & 366 & 2080 \\
\hline GO:0008026 & ATP-dependent helicase activity & $\mathrm{F}$ & 6.39E-09 & $7.10 \mathrm{E}-11$ & 24 & 15 & 39 & 366 & 2074 \\
\hline GO:0003924 & GTPase activity & $\mathrm{F}$ & $1.41 \mathrm{E}-08$ & $1.61 \mathrm{E}-10$ & 25 & 18 & 43 & 365 & 2071 \\
\hline GO:0004674 & protein serine/threonine kinase activity & $\mathrm{F}$ & 4.92E-08 & $6.17 \mathrm{E}-10$ & 25 & 20 & 45 & 365 & 2069 \\
\hline GO:0003755 & peptidyl-prolyl cis-trans isomerase activity & $\mathrm{F}$ & $5.29 \mathrm{E}-07$ & 7.72E-09 & 14 & 4 & 18 & 376 & 2085 \\
\hline GO:0004767 & sphingomyelin phosphodiesterase activity & $\mathrm{F}$ & 1.05E-04 & $2.28 \mathrm{E}-06$ & 7 & 0 & 7 & 383 & 2089 \\
\hline GO:0004298 & threonine-type endopeptidase activity & $\mathrm{F}$ & $1.21 \mathrm{E}-04$ & $2.74 \mathrm{E}-06$ & 8 & 1 & 9 & 382 & 2088 \\
\hline GO:0004842 & ubiquitin-protein ligase activity & $\mathrm{F}$ & 1.09E-03 & 2.96E-05 & 15 & 17 & 32 & 375 & 2072 \\
\hline GO:0005200 & structural constituent of cytoskeleton & $\mathrm{F}$ & 2.95E-03 & 8.91E-05 & 6 & 1 & 7 & 384 & 2088 \\
\hline GO:0008568 & microtubule-severing ATPase activity & $\mathrm{F}$ & 3.06E-03 & $9.43 E-05$ & 5 & 0 & 5 & 385 & 2089 \\
\hline GO:0042288 & MHC class I protein binding & $\mathrm{F}$ & $1.50 \mathrm{E}-02$ & $6.05 \mathrm{E}-04$ & 4 & 0 & 4 & 386 & 2089 \\
\hline GO:0005528 & FK506 binding & $\mathrm{F}$ & $1.50 \mathrm{E}-02$ & $6.05 \mathrm{E}-04$ & 4 & 0 & 4 & 386 & 2089 \\
\hline GO:0019899 & enzyme binding & $\mathrm{F}$ & 1.92E-02 & 8.08E-04 & 24 & 56 & 80 & 366 & 2033 \\
\hline GO:0003676 & nucleic acid binding & $\mathrm{F}$ & 2.13E-02 & $9.21 \mathrm{E}-04$ & 80 & 293 & 373 & 310 & 1796 \\
\hline GO:0007264 & small GTPase mediated signal transduction & $P$ & $1.78 \mathrm{E}-10$ & $1.24 \mathrm{E}-12$ & 25 & 12 & 37 & 365 & 2077 \\
\hline GO:0051258 & protein polymerization & $P$ & $2.72 \mathrm{E}-07$ & 3.75E-09 & 19 & 11 & 30 & 371 & 2078 \\
\hline GO:0006184 & GTP catabolic process & $P$ & 8.66E-07 & $1.32 \mathrm{E}-08$ & 24 & 23 & 47 & 366 & 2066 \\
\hline GO:0000413 & protein peptidyl-prolyl isomerization & $P$ & $2.30 \mathrm{E}-06$ & $3.94 \mathrm{E}-08$ & 13 & 4 & 17 & 377 & 2085 \\
\hline GO:0006468 & protein phosphorylation & $P$ & 2.76E-06 & 4.87E-08 & 34 & 52 & 86 & 356 & 2037 \\
\hline GO:0006200 & ATP catabolic process & $P$ & $5.78 \mathrm{E}-04$ & $1.50 \mathrm{E}-05$ & 16 & 18 & 34 & 374 & 2071 \\
\hline GO:0031145 & $\begin{array}{l}\text { anaphase-promoting complex-dependent } \\
\text { proteasomal ubiquitin-dependent protein catabolic } \\
\text { process }\end{array}$ & $P$ & $1.83 \mathrm{E}-03$ & $5.19 \mathrm{E}-05$ & 9 & 5 & 14 & 381 & 2084 \\
\hline GO:0000209 & protein polyubiquitination & $P$ & $2.90 \mathrm{E}-03$ & $8.70 \mathrm{E}-05$ & 12 & 12 & 24 & 378 & 2077 \\
\hline GO:0031110 & $\begin{array}{l}\text { regulation of microtubule polymerization or } \\
\text { depolymerization }\end{array}$ & $P$ & 3.06E-03 & $9.43 E-05$ & 5 & 0 & 5 & 385 & 2089 \\
\hline GO:0000165 & MAPK cascade & $P$ & $3.12 \mathrm{E}-03$ & $9.69 \mathrm{E}-05$ & 8 & 4 & 12 & 382 & 2085 \\
\hline GO:0030174 & $\begin{array}{l}\text { regulation of DNA-dependent DNA replication } \\
\text { initiation }\end{array}$ & $P$ & $3.12 \mathrm{E}-03$ & $9.69 \mathrm{E}-05$ & 8 & 4 & 12 & 382 & 2085 \\
\hline GO:0045087 & innate immune response & $P$ & 3.49E-03 & $1.11 \mathrm{E}-04$ & 10 & 8 & 18 & 380 & 2081 \\
\hline GO:0051437 & $\begin{array}{l}\text { positive regulation of ubiquitin-protein ligase activity } \\
\text { involved in mitotic cell cycle }\end{array}$ & $P$ & $5.31 \mathrm{E}-03$ & $1.77 \mathrm{E}-04$ & 7 & 3 & 10 & 383 & 2086 \\
\hline GO:0007018 & microtubule-based movement & $P$ & $6.73 \mathrm{E}-03$ & $2.30 \mathrm{E}-04$ & 12 & 14 & 26 & 378 & 2075 \\
\hline GO:0031346 & positive regulation of cell projection organization & $P$ & 8.65E-03 & 3.09E-04 & 6 & 2 & 8 & 384 & 2087 \\
\hline GO:0051495 & positive regulation of cytoskeleton organization & $P$ & 8.65E-03 & 3.09E-04 & 6 & 2 & 8 & 384 & 2087 \\
\hline GO:0000216 & M/G1 transition of mitotic cell cycle & $P$ & 1.13E-02 & 4.21E-04 & 7 & 4 & 11 & 383 & 2085 \\
\hline GO:0051084 & 'de novo' post-translational protein folding & $P$ & $1.29 \mathrm{E}-02$ & 4.92E-04 & 5 & 1 & 6 & 385 & 2088 \\
\hline GO:0000084 & S phase of mitotic cell cycle & $P$ & $1.45 \mathrm{E}-02$ & $5.71 \mathrm{E}-04$ & 10 & 11 & 21 & 380 & 2078 \\
\hline GO:0008356 & asymmetric cell division & $P$ & $1.50 \mathrm{E}-02$ & $6.05 \mathrm{E}-04$ & 4 & 0 & 4 & 386 & 2089 \\
\hline GO:0010458 & exit from mitosis & $P$ & $1.50 \mathrm{E}-02$ & $6.05 \mathrm{E}-04$ & 4 & 0 & 4 & 386 & 2089 \\
\hline GO:0071363 & cellular response to growth factor stimulus & $P$ & 1.69E-02 & $6.97 \mathrm{E}-04$ & 9 & 9 & 18 & 381 & 2080 \\
\hline GO:0051704 & multi-organism process & $P$ & $2.41 \mathrm{E}-02$ & $1.05 \mathrm{E}-03$ & 25 & 61 & 86 & 365 & 2028 \\
\hline GO:0051225 & spindle assembly & $P$ & 3.17E-02 & $1.50 \mathrm{E}-03$ & 5 & 2 & 7 & 385 & 2087 \\
\hline GO:0050684 & regulation of mRNA processing & $P$ & 3.17E-02 & $1.50 \mathrm{E}-03$ & 5 & 2 & 7 & 385 & 2087 \\
\hline GO:0006977 & $\begin{array}{l}\text { DNA damage response, signal transduction by p } 53 \\
\text { class mediator resulting in cell cycle arrest }\end{array}$ & $P$ & 3.17E-02 & $1.50 \mathrm{E}-03$ & 5 & 2 & 7 & 385 & 2087 \\
\hline GO:0007167 & enzyme linked receptor protein signaling pathway & $P$ & 3.31E-02 & $1.58 \mathrm{E}-03$ & 12 & 19 & 31 & 378 & 2070 \\
\hline GO:0051436 & $\begin{array}{l}\text { negative regulation of ubiquitin-protein ligase activity } \\
\text { involved in mitotic cell cycle }\end{array}$ & $P$ & $3.61 \mathrm{E}-02$ & $1.75 \mathrm{E}-03$ & 6 & 4 & 10 & 384 & 2085 \\
\hline GO:0030522 & intracellular receptor signaling pathway & $P$ & 4.64E-02 & $2.29 \mathrm{E}-03$ & 8 & 9 & 17 & 382 & 2080 \\
\hline GO:0045664 & regulation of neuron differentiation & $\mathrm{P}$ & 4.64E-02 & $2.29 \mathrm{E}-03$ & 8 & 9 & 17 & 382 & 2080 \\
\hline GO:0005874 & microtubule & C & 3.31E-06 & $5.93 \mathrm{E}-08$ & 21 & 19 & 40 & 369 & 2070 \\
\hline GO:0019773 & proteasome core complex, alpha-subunit complex & C & 1.05E-04 & $2.28 \mathrm{E}-06$ & 7 & 0 & 7 & 383 & 2089 \\
\hline GO:0045298 & tubulin complex & C & 3.06E-03 & $9.43 \mathrm{E}-05$ & 5 & 0 & 5 & 385 & 2089 \\
\hline GO:0005681 & spliceosomal complex & C & 5.33E-03 & $1.78 \mathrm{E}-04$ & 18 & 30 & 48 & 372 & 2059 \\
\hline GO:0048471 & perinuclear region of cytoplasm & C & 1.69E-02 & 7.00E-04 & 11 & 14 & 25 & 379 & 2075 \\
\hline GO:0005829 & cytosol & C & $2.00 \mathrm{E}-02$ & 8.53E-04 & 42 & 126 & 168 & 348 & 1963 \\
\hline GO:0005663 & DNA replication factor $\mathrm{C}$ complex & C & 3.17E-02 & $1.50 \mathrm{E}-03$ & 5 & 2 & 7 & 385 & 2087 \\
\hline
\end{tabular}

* ordered by category and significance 
conserved during the embryonic pharyngula or phylotypic period is generally mirrored by conserved expression patterns of conserved genes at these stages (Kalinka and Tomancak, 2012, Kalinka et al., 2010). In contrast, active transcription in the early zygote is much more limited. Early animal embryos instead largely rely upon RNAs and proteins provided by the maternal gonad during oocyte maturation. This transcriptionally-quiescent period might, a priori, be considered evolutionarily constrained, as the maternally provided transcriptome is widely considered to fulfill one major role, the initiation and management of several rounds of rapid cell division. Every one of these early cell divisions is a critical event that must be faithfully completed to ensure the development of a healthy embryo (Evsikov et al., 2006).

Few studies have investigated the level of conservation of maternally provided genes (Shen-Orr et al., 2010), despite their well-recognised importance in early development (Wieschaus, 1996). Indeed there are few comprehensive datasets of maternally provisioned transcripts even in well-characterised taxa, and none in the Lophotrochozoa. Improvements in sequencing technologies mean that quantitative transcriptome studies are now possible on organisms that lack genomic resources. Our work therefore provides a list of conserved maternal transcripts, or COMATs (Table 6; Supplementary Table 1), that may be useful to the wider community interested in the study of early bilaterian development.

We identified a core set of COMATs from seven representatives of the three bilaterian superphyla, spanning $>600$ million years of evolution (Peterson et al., 2008). These species display highly divergent modes of development (from direct to indirect, and mosaic to regulative). Since the $L$. stagnalis maternal transcriptome we report here is unlikely to be complete, one possibility is that our estimate of $5-10 \%$ of all maternally provisioned transcripts being conserved across the Bilateria may rise upon deeper sampling of the snail transcriptome. Conversely, the number may reduce as maternal transcriptomes from more taxa are included in the analysis.

Unsurprisingly, we found that many of these genes had nucleotide (especially ATP and GTP) binding functions, were associated with protein degradation or had activities associated with the cell cycle (Table 6). The majority of functions ascribed are probably accurately defined as housekeeping (Eisenberg and Levanon, 2013). One possibility is that some of the most conserved maternal RNAs are those that cannot be provided (solely) as proteins. Cell cycle genes may be illustrative, because some cell cycle proteins are degraded every cycle and so maternal protein alone cannot be sufficient. Finally, the fact that the $\sim 32$-cell transcriptome was neither enriched nor underrepresented for any gene ontology relative to the 1 to 2 -cell transcriptome, along with a relative overrepresentation of maternal-zygotic transcripts that are conserved between $M$. musculus / C. elegans and $L$. stagnalis suggests that the same transcripts are at least still present during early zygotic transcription (Supplementary Figure 1).

Given the wide variety of developmental modes and rates displayed by metazoan embryos, as well as the hourglass theory of evolution (Kalinka and Tomancak, 2012), one view is that we might expect to find relatively few deeply conserved maternal transcripts. Alternatively, as it has been documented that a relatively large fraction (between $45 \%$ and $75 \%$ ) of all genes within a species' genome can be found as maternal transcripts (see references within Tadros and Lipshitz, 2009), another view is that maternal transcripts that are conserved between different organisms may be a stochastic subset of a large maternal transcriptome. Instead, our analyses suggest that there is a core and specific set of maternal transcripts that may be essential for early cell divisions, irrespective of the precise mode of development.

While both our data and the others utilised in this study have obvious limitations, primarily the limited sequencing coverage, it is thus uncertain whether further investigation will reveal a greater or lesser proportion of conserved maternal transcripts. However, a simultaneous consideration is that we have detected those genes that are conserved and transcribed at a relatively high level across all taxa, since the study is at best partially quantitative. Further studies are warranted to reveal the true nature of this conservation. Nonetheless, as we found that the conserved maternal part of a well annotated group of $H$. sapiens housekeeping genes is enriched for precisely the same functions (Table 6, Supplementary Table 3), we can robustly conclude that there is undoubtedly highly conserved gene expression in the early development of bilaterian embryos. There may also be a distinct set of genes, with mostly housekeeping and nucleotide metabolic functions, that is a necessary starting point of the maternal-to-zygotic transition.

Our analyses thus suggest that the ancestral function of maternal provisioning in animal eggs is to supply the zygote with the materials with which to perform the basic cellular functions of rapid cell division in the early stages of development. The extent of the provisioning is evolutionarily labile, with species that have evolved rapid development relying more on maternal products. Addition of patterning molecules is phylogenetically contingent: as different groups and species have evolved different mechanisms of patterning the embryo and been under selection for fast patterning (as in lineage-driven, or mosaic development) or delayed patterning (as in species with regulative development), so the role of maternal factors in driving patterning has changed.

\section{Materials and Methods}

\section{cDNA library construction}

Early development in the pond snail $L$. stagnalis has been described in exquisite morphological and cytological detail (Raven, 1966). However, the L. stagnalis MZT has not been mapped in the same detail as in model species, but transcription from zygotic nuclei was first detected in 8-cell embryos, and major transcriptional activity detected at the 24-cell stage (Morrill, 1982). While division cycles are not as rapid as development in $C$. elegans or $D$. melanogaster, the $L$. stagnalis embryo does not divide for $\sim 3$ hour at the 24-cell stage, suggesting this may represent a shift from maternal to zygotic control. We thus separately sampled 1 to 2 -cell and $\sim 32$-cell stage $L$. stagnalis embryos from a laboratory stock maintained in Nottingham, representing the maternal component and the early stages of zygotic transcription. Zygotes were manually dissected out of their egg capsules and stored in RNAlater (Ambion). As one embryo was expected to yield $\sim 0.5 \mathrm{ng}$ RNA, more than one thousand individual embryos of each type were pooled. Total RNA was then extracted using the Qiagen RNeasy Plus Micro Kit. cDNA was then synthesised and two non-normalised cDNA libraries were constructed using the MINT system (Evrogen). The libraries were then processed for sequencing on the Roche 454 FLX platform in the Edinburgh Genomics facility, University of Edinburgh. The raw data have been submitted to the European Nucleotide Archive under bioproject PRJEB7773.

\section{Transcriptome assembly}

The raw Roche 454 data were screened for MINT and sequencing adapters and trimmed of low quality base calls. The reads from each library were 
TABLE 6

\section{THE 300 HUMAN GENES IN THE CONSERVED MATERNAL DATASET}

\begin{tabular}{|c|c|c|c|c|c|}
\hline Gene & Accession & Description & Gene & Accession & Description \\
\hline$\overline{\text { MTRR }}$ & NM_002454 & $\begin{array}{l}\text { 5-methyltetrahydrofolate-homocysteine methyltransferase } \\
\text { reductase }\end{array}$ & NOP5/NOP58 & NM_015934 & Nucleolar protein NOP5/NOP58 \\
\hline ACAD9 & NM_014049 & Acyl-Coenzyme A dehydrogenase family, member 9 & NAP1L4 & NM_005969 & Nucleosome assembly protein 1 -like 4 \\
\hline ACADVL & NM_000018 & Acyl-Coenzyme A dehydrogenase, very long chain & OTUB1 & NM_017670 & OTU domain, ubiquitin aldehyde binding 1 \\
\hline ARF1 & NM_001658 & ADP-ribosylation factor 1 & OSBPL2 & NM_014835 & Oxysterol binding protein-like 2 \\
\hline ARF5 & NM_001662 & ADP-ribosylation factor 5 & PAK2 & NM_002577 & P21 (CDKN1A)-activated kinase 2 \\
\hline ARF6 & NM_001663 & ADP-ribosylation factor 6 & PCAF & NM_003884 & P300/CBP-associated factor \\
\hline ARFGAP3 & NM_014570 & ADP-ribosylation factor GTPase activating protein 3 & PCTK1 & NM_006201 & PCTAIRE protein kinase 1 \\
\hline ARL1 & NM_001177 & ADP-ribosylation factor-like 1 & PPWD1 & NM_015342 & Peptidylprolyl isomerase domain and WD repeat containing 1 \\
\hline AHSA1 & NM_012111 & $\begin{array}{l}\text { AHA1, activator of heat shock 90kDa protein ATPase homolog } 1 \\
\text { (yeast) }\end{array}$ & PPIE & NM_006112 & Peptidylprolyl isomerase E (cyclophilin E) \\
\hline ALDH9A1 & NM_000696 & Aldehyde dehydrogenase 9 family, member A1 & PPIF & NM_005729 & Peptidylprolyl isomerase F (cyclophilin F) \\
\hline AAMP & NM_001087 & Angio-associated, migratory cell protein & PPIH & NM_006347 & Peptidylprolyl isomerase $\mathrm{H}$ (cyclophilin $\mathrm{H}$ ) \\
\hline ANKRD17 & NM_032217 & Ankyrin repeat domain 17 & PRDX1 & NM_002574 & Peroxiredoxin 1 \\
\hline ANKRD28 & NM_001195098 & Ankyrin repeat domain 28 & PRDX2 & NM_005809 & Peroxiredoxin 2 \\
\hline ARD1A & NM_003491 & ARD1 homolog A, N-acetyltransferase (S. cerevisiae) & PECl & NM_006117 & Peroxisomal D3,D2-enoyl-CoA isomerase \\
\hline ACTR1A & NM_005736 & ARP1 actin-related protein 1 homolog A, centractin alpha (yeast) & PI4KB & NM_002651 & Phosphatidylinositol 4-kinase, catalytic, beta \\
\hline ACTR1B & NM_005735 & ARP1 actin-related protein 1 homolog B, centractin beta (yeast) & PLAA & NM_001031689 & Phospholipase A2-activating protein \\
\hline ARNT & NM_001668 & Aryl hydrocarbon receptor nuclear translocator & PRPSAP1 & NM_002766 & Phosphoribosyl pyrophosphate synthetase-associated protein 1 \\
\hline ATP5A1 & NM_004046 & $\begin{array}{l}\text { ATP synthase, } \mathrm{H}+\text { transporting, mitochondrial F1 complex, alpha } \\
\text { subunit } 1\end{array}$ & PAFAH1B1 & NM_000430 & $\begin{array}{l}\text { Platelet-activating factor acetylhydrolase, isoform Ib, alpha } \\
\text { subunit } 45 \mathrm{kDa}\end{array}$ \\
\hline ATP5B & NM_001686 & $\begin{array}{l}\text { ATP synthase, } \mathrm{H}+\text { transporting, mitochondrial F1 complex, beta } \\
\text { polypeptide }\end{array}$ & PLRG1 & 2669 & Pleiotropic regulator 1 (PRL1 homolog, Arabidopsis) \\
\hline ATAD1 & NM_032810 & ATPase family, AAA domain containing 1 & PHB & NM_002634 & Prohibitin \\
\hline ABCB10 & NM_012089 & ATP-binding cassette, sub-family B (MDR/TAP), member 10 & PHB2 & NM_001144831 & Prohibitin 2 \\
\hline ABCB7 & NM_004299 & ATP-binding cassette, sub-family B (MDR/TAP), member 7 & PSMC2 & NM_002803 & Proteasome (prosome, macropain) 26S subunit, ATPase, 2 \\
\hline BXDC5 & NM_025065 & Brix domain containing 5 & PSMC3 & NM_002804 & Proteasome (prosome, macropain) 26S subunit, ATPase, 3 \\
\hline BRD7 & NM_013263 & Bromodomain containing 7 & PSMC4 & NM_006503 & Proteasome (prosome, macropain) 26S subunit, ATPase, 4 \\
\hline BPTF & NM_004459 & Bromodomain PHD finger transcription factor & PSMC5 & NM_002805 & Proteasome (prosome, macropain) 26S subunit, ATPase, 5 \\
\hline BUB3 & NM_004725 & BUB3 budding uninhibited by benzimidazoles 3 homolog (yeast) & PSMC6 & NM_002806 & Proteasome (prosome, macropain) 26S subunit, ATPase, 6 \\
\hline CAB39 & NM_016289 & Calcium binding protein 39 & PSMD10 & NM_002814 & Proteasome (prosome, macropain) 26S subunit, non-ATPase, 10 \\
\hline CALU & NM_001219 & Calumenin & PSMD11 & NM_002815 & Proteasome (prosome, macropain) 26S subunit, non-ATPase, 11 \\
\hline CBR4 & NM_032783 & Carbonyl reductase 4 & PSMA1 & NM_002786 & Proteasome (prosome, macropain) subunit, alpha type, 1 \\
\hline CSNK1A1 & NM_001892 & Casein kinase 1, alpha 1 & PSMA2 & NM_002787 & Proteasome (prosome, macropain) subunit, alpha type, 2 \\
\hline CSNK1D & NM_001893 & Casein kinase 1 , delta & PSMA3 & NM_002788 & Proteasome (prosome, macropain) subunit, alpha type, 3 \\
\hline CSNK2A3 & NM_001256686 & casein kinase 2 , alpha 3 polypeptide & PSMA4 & NM_002789 & Proteasome (prosome, macropain) subunit, alpha type, 4 \\
\hline CTCF & NM_006565 & CCСTC-binding factor (zinc finger protein) & PSMA5 & NM_002790 & Proteasome (prosome, macropain) subunit, alpha type, 5 \\
\hline CNBP & NM_003418 & $\mathrm{CCHC}$-type zinc finger, nucleic acid binding protein & PSMA6 & NM_002791 & Proteasome (prosome, macropain) subunit, alpha type, 6 \\
\hline CD63 & NM_001780 & CD63 molecule & PSMA7 & NM_002792 & Proteasome (prosome, macropain) subunit, alpha type, 7 \\
\hline CRKRS & NM_015083 & CDC2-related kinase, arginine/serine-rich & PSMB2 & NM_002794 & Proteasome (prosome, macropain) subunit, beta type, 2 \\
\hline CDC37 & NM_007065 & CDC37 homolog (S. cerevisiae) & PSMB6 & NM_002798 & Proteasome (prosome, macropain) subunit, beta type, 6 \\
\hline CDC42 & NM_001791 & CDC42 (GTP binding protein, 25kDa) & PSMB7 & NM_002799 & Proteasome (prosome, macropain) subunit, beta type, 7 \\
\hline CDC5L & NM_001253 & CDC5 CDC5-like (S. pombe) & PIAS1 & NM_016166 & Protein inhibitor of activated STAT, 1 \\
\hline CLK3 & NM_003992 & CDC-like kinase 3 & PRKAA1 & NM_006251 & Protein kinase, AMP-activated, alpha 1 catalytic subunit \\
\hline ССТЗ & NM_005998 & Chaperonin containing TCP1, subunit 3 (gamma) & PPP1CC & NM_002710 & Protein phosphatase 1 , catalytic subunit, gamma isoform \\
\hline СCT4 & NM_006430 & Chaperonin containing TCP1, subunit 4 (delta) & PPP2CB & NM_001009552 & $\begin{array}{l}\text { Protein phosphatase } 2 \text { (formerly } 2 \mathrm{~A} \text { ), catalytic subunit, beta } \\
\text { isoform }\end{array}$ \\
\hline ССТ5 & NM_012073 & Chaperonin containing TCP1, subunit 5 (epsilon) & PPP2R5D & NM_006245 & Protein phosphatase 2 , regulatory subunit $\mathrm{B}^{\prime}$, delta isoform \\
\hline ССТ6А & NM_001762 & Chaperonin containing TCP1, subunit 6A (zeta 1) & PPP4C & NM_002720 & Protein phosphatase 4 (formerly X), catalytic subunit \\
\hline ССТ7 & NM_006429 & Chaperonin containing TCP1, subunit 7 (eta) & PPP6C & NM_002721 & Protein phosphatase 6 , catalytic subunit \\
\hline ССТ8 & NM_006585 & Chaperonin containing TCP1, subunit 8 (theta) & PSKH1 & NM_006742 & Protein serine kinase $\mathrm{H} 1$ \\
\hline CHD4 & NM_001273 & Chromodomain helicase DNA binding protein 4 & PTPN1 & NM_002827 & Protein tyrosine phosphatase, non-receptor type 1 \\
\hline C14orf130 & NM_175748 & Chromosome 14 open reading frame 130 & PRPF31 & NM_015629 & PRP31 pre-mRNA processing factor 31 homolog (S. cerevisiae) \\
\hline CSTF1 & NM_001324 & Cleavage stimulation factor, 3 pre-RNA, subunit $1,50 \mathrm{kDa}$ & PRPF4 & NM_004697 & PRP4 pre-mRNA processing factor 4 homolog (yeast) \\
\hline CSTF2T & NM_015235 & $\begin{array}{l}\text { Cleavage stimulation factor, } 3 \text { ' pre-RNA, subunit } 2,64 \mathrm{kDa} \text {, tau } \\
\text { variant }\end{array}$ & PWP2 & NM_005049 & PWP2 periodic tryptophan protein homolog (yeast) \\
\hline COPA & NM_004371 & Coatomer protein complex, subunit alpha & RAB10 & NM_016131 & RAB10, member RAS oncogen \\
\hline COPS2 & NM_004236 & $\begin{array}{l}\text { COP9 constitutive photomorphogenic homolog subunit } 2 \\
\text { (Arabidopsis) }\end{array}$ & RAB11B & NM_004218 & RAB11B, member RAS oncogene family \\
\hline CTDSP2 & NM_005730 & $\begin{array}{l}\text { CTD (carboxy-terminal domain, RNA polymerase II, polypeptide } \\
\text { A) small phosphatase } 2\end{array}$ & RAB14 & NM_016322 & RAB14, member RAS oncogene family \\
\hline CLEC3B & NM_015004 & C-type lectin domain family 3 , member B & RAB18 & NM_021252 & RAB18, member RAS oncogene family \\
\hline CUL1 & NM_003592 & Cullin 1 & RAB1A & NM_004161 & RAB1A, member RAS oncogene family \\
\hline CUL4B & NM_003588 & Cullin 4B & RAB2A & NM_002865 & RAB2A, member RAS oncogene family \\
\hline CDK9 & NM_001261 & Cyclin-dependent kinase 9 & RAB5C & NM_004583 & RAB5C, member RAS oncogene family \\
\hline CYB5B & NM_030579 & Cytochrome b5 type B (outer mitochondrial membrane) & RAB7A & NM_004637 & RAB7A, member RAS oncogene family \\
\hline CYP2U1 & NM_183075 & Cytochrome P450, family 2, subfamily U, polypeptide 1 & $\mathrm{RDX}$ & NM_002906 & Radixin \\
\hline DAZAP1 & NM_018959 & DAZ associated protein 1 & RANBP1 & NM_002882 & RAN binding protein 1 \\
\hline DDX19B & NM_007242 & DEAD (Asp-Glu-Ala-As) box polypeptide 19B & RAN & NM_006325 & RAN, member RAS oncogene family \\
\hline DDX1 & NM_004939 & DEAD (Asp-Glu-Ala-Asp) box polypeptide 1 & RAP1A & NM_002884 & RAP1A, member of RAS oncogene family \\
\hline DDX17 & NM_006386 & DEAD (Asp-Glu-Ala-Asp) box polypeptide 17 & $\mathrm{RHOA}$ & NM_001664 & Ras homolog gene family, member A \\
\hline DDX18 & NM_006773 & DEAD (Asp-Glu-Ala-Asp) box polypeptide 18 & REST & NM_005612 & RE1-silencing transcription factor \\
\hline DDX21 & NM_004728 & DEAD (Asp-Glu-Ala-Asp) box polypeptide 21 & RFC2 & NM_002914 & Replication factor C (activator 1) 2, 40kDa \\
\hline DDX23 & NM_004818 & DEAD (Asp-Glu-Ala-Asp) box polypeptide 23 & RFC5 & NM_007370 & Replication factor C (activator 1) $5,36.5 \mathrm{kDa}$ \\
\hline DDX24 & NM_020414 & DEAD (Asp-Glu-Ala-Asp) box polypeptide 24 & RBBP4 & NM_005610 & Retinoblastoma binding protein 4 \\
\hline DDX27 & NM_017895 & DEAD (Asp-Glu-Ala-Asp) box polypeptide 27 & RXRA & NM_002957 & Retinoid $\mathrm{X}$ receptor, alpha \\
\hline DDX3X & NM_001356 & DEAD (Asp-Glu-Ala-Asp) box polypeptide 3, X-linked & $\mathrm{RDH} 14$ & NM_020905 & Retinol dehydrogenase 14 (all-trans/9-cis/11-cis) \\
\hline DDX41 & NM_016222 & DEAD (Asp-Glu-Ala-Asp) box polypeptide 41 & REXO1 & NM_020695 & REX1, RNA exonuclease 1 homolog (S. cerevisiae) \\
\hline DDX47 & NM_016355 & DEAD (Asp-Glu-Ala-Asp) box polypeptide 47 & RPL14 & NM_003973 & Ribosomal protein L14 \\
\hline DDX54 & NM_024072 & DEAD (Asp-Glu-Ala-Asp) box polypeptide 54 & RPL35 & NM_007209 & Ribosomal protein L35 \\
\hline DDX56 & NM_019082 & DEAD (Asp-Glu-Ala-Asp) box polypeptide 56 & RPS6KB1 & NM_003161 & Ribosomal protein S6 kinase, $70 \mathrm{kDa}$, polypeptide 1 \\
\hline
\end{tabular}


TABLE 6 (CONTINUED)

\section{THE 300 HUMAN GENES IN THE CONSERVED MATERNAL DATASET}

\begin{tabular}{|c|c|c|c|c|c|}
\hline Gene & Accession & Description & Gene & Accession & Description \\
\hline$\overline{\mathrm{DHX} 15}$ & NM_001358 & DEAH (Asp-Glu-Ala-His) box polypeptide 15 & RPS6KB2 & NM_003952 & Ribosomal protein S6 kinase, $70 \mathrm{kDa}$, polypeptide 2 \\
\hline DHX38 & NM_014003 & DEAH (Asp-Glu-Ala-His) box polypeptide 38 & RPS6KA3 & NM_004586 & Ribosomal protein S6 kinase, 90kDa, polypeptide 3 \\
\hline DHX8 & NM_004941 & DEAH (Asp-Glu-Ala-His) box polypeptide 8 & RRP1 & NM_003683 & Ribosomal RNA processing 1 homolog (S. cerevisiae) \\
\hline DHRS7B & NM_015510 & Dehydrogenase/reductase (SDR family) member 7B & $\mathrm{AHCY}$ & NM_000687 & S-adenosylhomocysteine hydrolase \\
\hline DLG1 & NM_004087 & Discs, large homolog 1 (Drosophila) & SCRIB & NM_015356 & Scribbled homolog (Drosophila) \\
\hline DNAJA2 & NM_005880 & DNAJ (Hsp40) homolog, subfamily A, member 2 & STRAP & NM_007178 & Serine/threonine kinase receptor associated protein \\
\hline DNAJA3 & NM_005147 & DNAJ (Hsp40) homolog, subfamily A, member 3 & SETD8 & NM_020382 & SET domain containing (lysine methyltransferase) 8 \\
\hline DNAJB12 & NM_017626 & DNAJ (Hsp40) homolog, subfamily B, member 12 & SMAD5 & NM_005903 & SMAD family member 5 \\
\hline DNAJC10 & NM_018981 & DNAJ (Hsp40) homolog, subfamily C, member 10 & SMU1 & NM_018225 & Smu- 1 suppressor of mec-8 and unc- 52 homolog (C. elegans) \\
\hline DNAJC17 & NM_018163 & DNAJ (Hsp40) homolog, subfamily C, member 17 & $\mathrm{SHOC2}$ & NM_007373 & Soc-2 suppressor of clear homolog (C. elegans) \\
\hline DNAJC5 & NM_025219 & DNAJ (Hsp40) homolog, subfamily C, member 5 & SLC25A11 & NM_003562 & $\begin{array}{l}\text { Solute carrier family } 25 \text { (mitochondrial carrier; oxoglutarate } \\
\text { carrier), member } 11\end{array}$ \\
\hline DUSP16 & NM_030640 & Dual specificity phosphatase 16 & SLC25A39 & NM_016016 & Solute carrier family 25 , member 39 \\
\hline ELAVL1 & NM_001419 & $\begin{array}{l}\text { ELAV (embryonic lethal, abnormal vision, Drosophila)-like } 1 \text { (Hu } \\
\text { antigen R) }\end{array}$ & SLC39A7 & NM_006979 & Solute carrier family 39 (zinc transporter), member 7 \\
\hline ETFA & NM_000126 & $\begin{array}{l}\text { Electron-transfer-flavoprotein, alpha polypeptide (glutaric aciduria } \\
\text { II) }\end{array}$ & SPG7 & NM_003119 & Spastic paraplegia 7 (pure and complicated autosomal recessive) \\
\hline ECHS1 & NM_004092 & Enoyl Coenzyme A hydratase, short chain, 1, mitochondrial & SPATA5L1 & NM_024063 & Spermatogenesis associated 5 -like 1 \\
\hline ERGIC2 & NM_016570 & ERGIC and golgi 2 & SFRS2 & NM_003016 & Splicing factor, arginine/serine-rich 2 \\
\hline EEF2 & NM_001961 & Eukaryotic translation elongation factor 2 & SAE1 & NM_005500 & SUMO1 activating enzyme subunit 1 \\
\hline EIF2AK3 & NM_004836 & Eukaryotic translation initiation factor 2-alpha kinase 3 & UBA2 & NM_005499 & SUMO1 activating enzyme subunit 2 \\
\hline EIF3D & NM_003753 & Eukaryotic translation initiation factor 3 , subunit $\mathrm{D}$ & TAF5L & NM_014409 & $\begin{array}{l}\text { TAF5-like RNA polymerase II, p300/CBP-associated factor } \\
\text { (PCAF)-associated factor, } 65 \mathrm{kDa}\end{array}$ \\
\hline EIF3I & NM_003757 & Eukaryotic translation initiation factor 3 , subunit I & TNKS2 & NM_025235 & $\begin{array}{l}\text { Tankyrase, TRF1-interacting ankyrin-related ADP-ribose } \\
\text { polymerase } 2\end{array}$ \\
\hline EIF4A1 & NM_001416 & Eukaryotic translation initiation factor $4 \mathrm{~A}$, isoform 1 & TCP1 & NM_030752 & T-complex 1 \\
\hline EIF4A3 & NM_014740 & Eukaryotic translation initiation factor $4 \mathrm{~A}$, isoform 3 & TXN2 & NM_012473 & Thioredoxin 2 \\
\hline EIF4E2 & NM_004846 & Eukaryotic translation initiation factor 4E family member 2 & TXNDC9 & NM_005783 & Thioredoxin domain containing 9 \\
\hline FBXW11 & NM_012300 & F-box and WD repeat domain containing 11 & TIAL1 & NM_003252 & TIA1 cytotoxic granule-associated RNA binding protein-like 1 \\
\hline FZR1 & NM_016263 & Fizzy/CDC20 related 1 (Drosophila) & TRAP1 & NM_001272049 & TNF receptor-associated protein 1 \\
\hline FKBP3 & NM_002013 & FK506 binding protein $3,25 \mathrm{kDa}$ & TOMM70A & NM_014820 & $\begin{array}{l}\text { Translocase of outer mitochondrial membrane } 70 \text { homolog A (S. } \\
\text { cerevisiae) }\end{array}$ \\
\hline FTSJ1 & NM_012280 & FtsJ homolog 1 (E. coli) & TPI1 & NM_000365 & Triosephosphate isomerase 1 \\
\hline FUSIP1 & NM_006625 & FUS interacting protein (serine/arginine-rich) 1 & TUFM & NM_003321 & Tu translation elongation factor, mitochondrial \\
\hline GTF2B & NM_001514 & General transcription factor IIB & TUBA1B & NM_006082 & Tubulin, alpha 1b \\
\hline GNPDA1 & NM_005471 & Glucosamine-6-phosphate deaminase 1 & TUBA1C & NM_032704 & Tubulin, alpha 1c \\
\hline GRWD1 & NM_031485 & Glutamate-rich WD repeat containing 1 & TUBB & NM_178014 & Tubulin, beta \\
\hline GRPEL1 & NM_025196 & GrpE-like 1, mitochondrial (E. coli) & YWHAB & NM_003404 & $\begin{array}{l}\text { Tyrosine 3-monooxygenase/tryptophan 5-monooxygenase } \\
\text { activation protein, beta polypeptide }\end{array}$ \\
\hline GTPBP4 & NM_012341 & GTP binding protein 4 & YWHAE & NM_006761 & $\begin{array}{l}\text { Tyrosine 3-monooxygenase/tryptophan 5-monooxygenase } \\
\text { activation protein, epsilon polypeptide }\end{array}$ \\
\hline GTPBP10 & NM_033107 & GTP-binding protein 10 (putative) & UBA52 & NM_003333 & Ubiquitin A-52 residue ribosomal protein fusion product 1 \\
\hline GNL2 & NM_013285 & Guanine nucleotide binding protein-like 2 (nucleolar) & UBB & NM_018955 & Ubiquitin B \\
\hline GNL3 & NM_014366 & Guanine nucleotide binding protein-like 3 (nucleolar) & UBC & NM_021009 & Ubiquitin C \\
\hline H2AFV & NM_012412 & $\mathrm{H} 2 \mathrm{~A}$ histone family, member $\mathrm{V}$ & UBE3C & NM_014671 & Ubiquitin protein ligase $\mathrm{E} 3 \mathrm{C}$ \\
\hline HBS1L & NM_006620 & HBS1-like (S. cerevisiae) & UBA3 & NM_003968 & Ubiquitin-activating enzyme E1C (UBA3 homolog, yeast) \\
\hline HSPE1 & NM_001202485 & Heat shock $10 \mathrm{kDa}$ protein 1 (chaperonin 10 ) & UBE2V1 & NM_021988 & Ubiquitin-conjugating enzyme E2 variant 1 \\
\hline HSPA5 & NM_005347 & Heat shock 70kDa protein 5 (glucose-regulated protein, $78 \mathrm{kDa}$ ) & UBE2A & NM_003336 & Ubiquitin-conjugating enzyme E2A (RAD6 homolog) \\
\hline HSPA8 & NM_006597 & Heat shock $70 \mathrm{kDa}$ protein 8 & UBE2B & NM_003337 & Ubiquitin-conjugating enzyme E2B (RAD6 homolog) \\
\hline HSPA9 & NM_004134 & Heat shock $70 \mathrm{kDa}$ protein 9 (mortalin) & UBE2D2 & NM_003339 & Ubiquitin-conjugating enzyme E2D 2 (UBC4/5 homolog, yeast) \\
\hline HGS & NM_004712 & Hepatocyte growth factor-regulated tyrosine kinase substrate & UBE2D3 & NM_003340 & Ubiquitin-conjugating enzyme E2D 3 (UBC4/5 homolog, yeast) \\
\hline HNRPD & NM_002138 & $\begin{array}{l}\text { Heterogeneous nuclear ribonucleoprotein } \mathrm{D} \text { (AU-rich element } \\
\text { RNA binding protein 1) }\end{array}$ & UBE2G2 & NM_003343 & Ubiquitin-conjugating enzyme E2G 2 (UBC7 homolog, yeast) \\
\hline HAT1 & NM_003642 & Histone acetyltransferase 1 & UBE2I & NM_003345 & Ubiquitin-conjugating enzyme E2I (UBC9 homolog, yeast) \\
\hline BAT1 & NM_004640 & HLA-B associated transcript 1 & UBE2N & NM_003348 & Ubiquitin-conjugating enzyme E2N (UBC13 homolog, yeast) \\
\hline IMP4 & NM_033416 & IMP4, U3 small nucleolar ribonucleoprotein, homolog (yeast) & UBE2Q1 & NM_017582 & Ubiquitin-conjugating enzyme E2Q (putative) 1 \\
\hline JAK1 & NM_002227 & Janus kinase 1 (a protein tyrosine kinase) & UBE2R2 & NM_017811 & Ubiquitin-conjugating enzyme E2R 2 \\
\hline KPNA1 & NM_002264 & Karyopherin alpha 1 (importin alpha 5) & VRK2 & NM_006296 & Vaccinia related kinase 2 \\
\hline KLHL8 & NM_020803 & Kelch-like 8 (Drosophila) & VPS4A & NM_013245 & Vacuolar protein sorting 4 homolog A (S. cerevisiae) \\
\hline L3MBTL2 & NM_031488 & L(3)mbt-like 2 (Drosophila) & AKT1 & NM_005163 & V-akt murine thymoma viral oncogene homolog 1 \\
\hline LRRC47 & NM_020710 & Leucine rich repeat containing 47 & VCP & NM_007126 & Valosin-containing protein \\
\hline MAPRE2 & NM_014268 & Microtubule-associated protein, RP/EB family, member 2 & VBP1 & NM_003372 & Von Hippel-Lindau binding protein 1 \\
\hline MCM7 & NM_005916 & Minichromosome maintenance complex component 7 & RALA & NM_005402 & V-ral simian leukemia viral oncogene homolog A (ras related) \\
\hline MRPL4 & NM_015956 & Mitochondrial ribosomal protein L4 & WDR12 & NM_018256 & WD repeat domain 12 \\
\hline MAPK1 & NM_002745 & Mitogen-activated protein kinase 1 & WDR3 & NM_006784 & WD repeat domain 3 \\
\hline MAPK9 & NM_002752 & Mitogen-activated protein kinase 9 & WDR57 & NM_004814 & WD repeat domain 57 (U5 snRNP specific) \\
\hline MAP2K1 & NM_002755 & Mitogen-activated protein kinase kinase 1 & WDR5B & NM_019069 & WD repeat domain $5 B$ \\
\hline MAP2K2 & NM_030662 & Mitogen-activated protein kinase kinase 2 & WDR61 & NM_025234 & WD repeat domain 61 \\
\hline MAP2K5 & NM_002757 & Mitogen-activated protein kinase kinase 5 & YPEL2 & NM_001005404 & Yippee-like 2 (Drosophila) \\
\hline MAP4K4 & NM_004834 & Mitogen-activated protein kinase kinase kinase kinase 4 & YME1L1 & NM_014263 & YME1-like 1 (S. cerevisiae) \\
\hline MAPKAPK2 & NM_004759 & Mitogen-activated protein kinase-activated protein kinase 2 & YY1 & NM_003403 & YY1 transcription factor \\
\hline MLH1 & NM_000249 & MutL homolog 1, colon cancer, nonpolyposis type 2 (E. coli) & ZBTB6 & NM_006626 & Zinc finger and BTB domain containing 6 \\
\hline MLLT1 & NM_005934 & $\begin{array}{l}\text { Myeloid/lymphoid or mixed-lineage leukemia (trithorax homolog, } \\
\text { Drosophila); translocated to, } 1\end{array}$ & ZNF138 & NM_001271649 & zinc finger protein 138 \\
\hline MYNN & NM_018657 & Myoneurin & ZNF195 & NM_007152 & Zinc finger protein 195 \\
\hline MYO1E & NM_004998 & Myosin IE & ZNF197 & NM_006991 & Zinc finger protein 197 \\
\hline MTMR1 & NM_003828 & Myotubularin related protein 1 & ZNF289 & NM_032389 & Zinc finger protein 289 , ID1 regulated \\
\hline NDUFS8 & NM_002496 & $\begin{array}{l}\text { NADH dehydrogenase (ubiquinone) Fe-S protein } 8,23 \mathrm{kDa} \\
\text { (NADH-coenzyme Q reductase) }\end{array}$ & ZNF347 & NM_032584 & Zinc finger protein 347 \\
\hline NEDD8 & NM_006156 & $\begin{array}{l}\text { Neural precursor cell expressed, developmentally down- } \\
\text { regulated } 8\end{array}$ & ZNF37A & NM_003421 & protein $37 \mathrm{~A}$ \\
\hline NF2 & NM_000268 & Neurofibromin 2 (bilateral acoustic neuroma) & ZNF397 & NM_001135178 & Zinc finger protein 397 \\
\hline
\end{tabular}


TABLE 6 (CONTINUED)

\section{THE 300 HUMAN GENES IN THE CONSERVED MATERNAL DATASET}

\begin{tabular}{|c|c|c|c|c|c|}
\hline Gene & Accession & Description & Gene & Accession & Description \\
\hline NHP2L1 & NM_005008 & NHP2 non-histone chromosome protein 2-like 1 (S. cerevisiae) & ZNF41 & NM_007130 & Zinc finger protein 41 \\
\hline NEK4 & NM_003157 & NIMA (never in mitosis gene a)-related kinase 4 & ZNF506 & NM_001099269 & Zinc finger protein 506 \\
\hline NSUN2 & NM_017755 & NOL1/NOP2/Sun domain family, member 2 & ZNF91 & NM_003430 & Zinc finger protein 91 \\
\hline NOL1 & NM_006170 & Nucleolar protein $1,120 \mathrm{kDa}$ & ZFAND1 & NM_024699 & Zinc finger, AN1-type domain 1 \\
\hline NOL5A & NM_006392 & Nucleolar protein $5 \mathrm{~A}$ (56kDa with KKE/D repeat) & ZFAND5 & NM_006007 & Zinc finger, AN1-type domain 5 \\
\hline NOLA2 & NM_017838 & $\begin{array}{l}\text { Nucleolar protein family } \mathrm{A} \text {, member } 2(\mathrm{H} / \mathrm{ACA} \text { small nucleolar } \\
\text { RNPS) }\end{array}$ & ZDHHC5 & NM_015457 & Zinc finger, DHHC-type containing 5 \\
\hline NOLA3 & NM_018648 & $\begin{array}{l}\text { Nucleolar protein family A, member } 3(\mathrm{H} / \mathrm{ACA} \text { small nucleolar } \\
\text { RNPS) }\end{array}$ & ZRF1 & NM_014377 & Zuotin related factor 1 \\
\hline
\end{tabular}

assembled using gsAssembler (version 2.6; also known as Newbler; 454 Life Sciences) and MIRA (Chevreux et al., 2004) separately, and then the two assemblies were assembled together using CAP3 (Huang and Madan, 1999), following the proposed best practice for transcriptome assembly from 454 data (Kumar and Blaxter, 2010). gsAssembler assemblies were run with the -cdna and -urt options. MIRA assemblies used job options 'denovo, est, accurate, 454' and with clipping by quality off (-CL:qc=no). CD-HIT was then used to remove redundant sequences from the merged CAP3 assemblies (Li and Godzik, 2006), running cd-hit-est with sequence identity threshold 0.98 (-c 0.98) and clustering to most similar cluster (-g 1). The assembly has been made available on afterParty (http://afterparty. bio.ed.ac.uk).

\section{Maternal transcriptomes from other species}

We identified a number of published, high-throughput, maternal transcriptome studies from Ciona intestinalis (Urochordata, Deutrostomia), Danio rerio, Mus musculus, Homo sapiens (Chordata, Deuterostomia), C. elegans (Nematoda, Ecdysozoa) and D. melanogaster (Arthropoda, Ecdysozoa). A "maternal transcript" is an mRNA that is present in the embryo before the initiation of major zygotic transcription. This does not mean that these mRNAs are not also later also transcribed from the zygotic genome in the developing embryo.

We carried out a reciprocal tBLASTx comparison of the $L$. stagnalis 1 to 2-cell transcriptome against each of the other datasets, using a threshold expect value of $1 \mathrm{e}^{-10}$. By identifying $L$. stagnalis transcripts that had homologues in all of the species we identified a putative set of conserved bilaterian maternal transcripts.

\section{Functional annotation of transcriptome}

The 1 to 2-cell and 32-cell transcriptome assemblies were annotated with gene ontology $(\mathrm{GO})$ terms using Blast2GO $v 2.7 .0$ against the NCBI non-redundant (nr) protein database, with an E-value cutoff of 1e-05. GO term distribution was quantified using the Combined Graph function of Blast2GO, with enrichment assessed using the Fisher's Exact Test function (Conesa et al., 2005).

\section{In situ validation of representative transcripts}

We validated the maternal expression of a selection of sequences in $L$. stagnalis 1 -cell embryos by using whole mount in situ hybridisation (WMISH). Primers were designed to amplify fragments of selected genes, which were then cloned into pGEM-T and verified by standard Sanger sequencing. Complementary riboprobes were prepared from these templates as described in Jackson et al., (2007a). The WMISH protocol we employed here for $L$. stagnalis is similar to previously described protocols for molluscan embryos and larvae (Jackson et al., 2006, Jackson et al., 2007b) with some important modifications (described elsewhere; in review). The colour reactions for all hybridisations (including the negative $\beta$-tubulin control) were allowed to proceed for the same length of time, and all samples cleared in $60 \%$ glycerol and imaged under a Zeiss Axio Imager Z1 microscope. The primers used are shown in Table 1.

\section{Acknowledgements}

The authors would like to thank The GenePool Genomics Facility (now Edinburgh Genomics), University of Edinburgh for generating the DNA sequences used in this study. Thanks to Karim Gharbi, Marian Thompson and colleagues at the GenePool, Aziz Aboobaker, as well as Eli Eisenberg for helpful advice on the human housekeeping data. Two anonymous referees provided helpful comments and advice. The work was principally funded by Biotechnology and Biological Sciences Research Council grant $B B / F 018940 / 1$ to $A D$ and MLB with additional funding provided by the Universities of Edinburgh and Nottingham, the Wellcome Trust Sanger Institute (WT098051), Biotechnology and Biological Sciences Research Council grants G00661X and F021135; Medical Research Council grant (G0900740) and Natural Environmental Research Council grant (R8/ $H 10 / 56)$ to MLB. The funders had no role in study design, data collection and analysis, decision to publish, or preparation of the manuscript. DJJ is funded by the German Excellence Initiative and DFG project JA 2108/1-2.

\section{References}

AANES, H., WINATA, C.L., LIN, C.H., CHEN, J.P., SRINIVASAN, K.G., LEE, S.G.P., LIM, A.Y.M., HAJAN, H.S., COLLAS, P., BOURQUE, G. et al., (2011). Zebrafish mRNA sequencing deciphers novelties in transcriptome dynamics during maternal to zygotic transition. Genome Research 21: 1328-1338.

ADEMA, C.M., LUO, M.-Z., HANELT, B., HERTEL, L.A., MARSHALL, J.J., ZHANG S.-M., DEJONG, R.J., KIM, H.-R., KUDRNA, D., WING, R.A. et al., (2006). A bacterial artificial chromosome library for Biomphalaria glabrata, intermediate snail host of Schistosoma mansoni. Memorias do Instituto Oswaldo Cruz 101 Suppl 1: 167-177.

AZUMI, K., SABAU, S.V., FUJIE, M., USAMI, T., KOYANAGI, R., KAWASHIMA, T., FUJIWARA, S., OGASAWARA, M., SATAKE, M., NONAKA, M. et al., (2007) Gene expression profile during the life cycle of the urochordate Ciona intestinalis. Developmental Biology 308: 572-582.

BAROUX, C., AUTRAN, D., GILLMOR, C.S., GRIMANELLI, D. and GROSSNIKLAUS, U. (2008). The Maternal to Zygotic Transition in Animals and Plants. In Control and Regulation of Stem Cells, vol. 73 (ed. STILLMAN, B.STEWART, S. and GRODZICKER, T.), pp.89-100.

BAUGH, L.R., HILL, A.A., SLONIM, D.K., BROWN, E.L. and HUNTER, C.P. (2003). Composition and dynamics of the Caenorhabditis elegans early embryonic transcriptome. Development 130: 889-900.

BENOIT, B., HE, C.H., ZHANG, F., VOTRUBA, S.M., TADROS, W., WESTWOOD J.T., SMIBERT, C.A., LIPSHITZ, H.D. and THEURKAUF, W.E. (2009). An essential role for the RNA-binding protein Smaug during the Drosophila maternal-to-zygotic transition. Development 136: 923-932.

BOYCOTT, A.E. and DIVER, C. (1923). On the inheritance of sinistrality in Limnaea peregra. Proceedings of the Royal Society Biological Sciences Series B95:207-213.

CHEVREUX, B., PFISTERER, T., DRESCHER, B., DRIESEL, A.J., MULLER, W.E.G., WETTER, T. and SUHAI, S. (2004). Using the miraEST assembler for reliable and automated mRNA transcript assembly and SNP detection in sequenced ESTs. Genome Research 14: 1147-1159.

COLLART, C., ALLEN, G.E., BRADSHAW, C.R., SMITH, J.C. and ZEGERMAN, P. (2013). Titration of four replication factors is essential for the Xenopus laevis 
midblastula transition. Science 341: 893-896.

CONESA, A., GOTZ, S., GARCIA-GOMEZ, J.M., TEROL, J., TALON, M. and ROBLES, M. (2005). Blast2GO: a universal tool for annotation, visualization and analysis in functional genomics research. Bioinformatics 21: 3674-3676.

DE RENZIS, S., ELEMENTO, O., TAVAZOIE, S. and WIESCHAUS, E.F. (2007). Unmasking activation of the zygotic genome using chromosomal deletions in the Drosophila embryo. Plos Biology 5: 1036-1051.

DILL, K.K. and SEAVER, E.C. (2008). Vasa and nanos are coexpressed in somatic and germ line tissue from early embryonic cleavage stages through adulthood in the polychaete Capitella sp I. Development Genes and Evolution 218: 453-463.

EISENBERG, E. and LEVANON, E.Y. (2013). Human housekeeping genes, revisited. Trends in Genetics 29: 569-574.

EVSIKOV, A.V., GRABER, J.H., BROCKMAN, J.M., HAMPL, A., HOLBROOK, A.E., SINGH, P., EPPIG, J.J., SOLTER, D. and KNOWLES, B.B. (2006). Cracking the egg: molecular dynamics and evolutionary aspects of the transition from the fully grown oocyte to embryo. Genes \& Development 20: 2713-2727.

GIANI, V.C., JR., YAMAGUCHI, E., BOYLE, M.J. and SEAVER, E.C. (2011). Somatic and germline expression of piwi during development and regeneration in the marine polychaete annelid Capitella teleta. Evodevo 2.

GILBERT, S.F. (2006). Developmental Biology. Sinauer, Sunderland, MA.

GRONDAHL, M.L., ANDERSEN, C.Y., BOGSTAD, J., NIELSEN, F.C., MEINERTZ, H. and BORUP, R. (2010). Gene expression profiles of single human mature oocytes in relation to age. Human Reproduction 25: 957-968.

HARADA, Y., HOSOIRI, Y. and KURODA, R. (2004). Isolation and evaluation of dextralspecific and dextral-enriched cDNA clones as candidates for the handednessdetermining gene in a freshwater gastropod, Lymnaea stagnalis. Development Genes and Evolution 214: 159-169.

HENRY, J.J., PERRY, K.J., FUKUI, L. and ALVI, N. (2010). Differential Localization of mRNAs During Early Development in the Mollusc, Crepidula fornicata. Integrative and Comparative Biology 50: 720-733.

HUANG, X.Q. and MADAN, A. (1999). CAP3: A DNA sequence assembly program. Genome Research 9: 868-877.

HUI, J.H.L., RAIBLE, F., KORCHAGINA, N., DRAY, N., SAMAIN, S., MAGDELENAT, G., JUBIN, C., SEGURENS, B., BALAVOINE, G., ARENDT, D. et al., (2009). Features of the ancestral bilaterian inferred from Platynereis dumerilii ParaHox genes. Bmc Biology 7.

JACKSON, D.J., MACIS, L., REITNER, J., DEGNAN, B.M. and WOERHEIDE, G. (2007a). Sponge paleogenomics reveals an ancient role for carbonic anhydrase in skeletogenesis. Science 316: 1893-1895.

JACKSON, D.J., MCDOUGALL, C., GREEN, K., SIMPSON, F., WORHEIDE, G. and DEGNAN, B.M. (2006). A rapidly evolving secretome builds and patterns a sea shell. Bmc Biology 4.

JACKSON, D.J., WORHEIDE, G. and DEGNAN, B.M. (2007b). Dynamic expression of ancient and novel molluscan shell genes during ecological transitions. BMC Evolutionary Biology 7.

KALINKA, A.T. and TOMANCAK, P. (2012). The evolution of early animal embryos: conservation or divergence? Trends in Ecology \& Evolution 27: 385-393.

KALINKA, A.T., VARGA, K.M., GERRARD, D.T., PREIBISCH, S., CORCORAN, D.L., JARRELLS, J., OHLER, U., BERGMAN, C.M. and TOMANCAK, P. (2010). Gene expression divergence recapitulates the developmental hourglass model. Nature 468: 811-U102.

KNIGHT, M., ITTIPRASERT, W., ODOEMELAM, E.C., ADEMA, C.M., MILLER, A., RAGHAVAN, N. and BRIDGER, J.M. (2011). Non-random organization of the Biomphalariaglabratagenome in interphase Bge cells and the spatial repositioning of activated genes in cells co-cultured with Schistosoma mansoni. International Journal for Parasitology 41: 61-70.

KUMAR, S. and BLAXTER, M.L. (2010). Comparing de novo assemblers for 454 transcriptome data. BMC Genomics 11.

KURODA, R., ENDO, B., ABE, M. and SHIMIZU, M. (2009). Chiral blastomere arrangement dictates zygotic left-right asymmetry pathway in snails. Nature 462: 790-794.

LAMBERT, J.D., CHAN, X.Y., SPIECKER, B. and SWEET, H.C. (2010). Characterizing the embryonic transcriptome of the snail llyanassa. Integrative and Comparative Biology 50: 768-777.

LAMBERT, J.D. and NAGY, L.M. (2002). Asymmetric inheritance of centrosomally localized mRNAs during embryonic cleavages. Nature 420: 682-686.

LEE, M.T., BONNEAU, A.R., TAKACS, C.M., BAZZINI, A.A., DIVITO, K.R., FLEMING E.S. and GIRALDEZ, A.J. (2013). Nanog, Pou5f1 and SoxB1 activate zygotic gene expression during the maternal-to-zygotic transition. Nature 503: 360-364.

LEICHSENRING, M., MAES, J., MOESSNER, R., DRIEVER, W. and ONICHTCHOUK, D. (2013). Pou5f1 transcription factor controls zygotic gene activation in vertebrates. Science 341: 1005-1009.

LI, W.Z. and GODZIK, A. (2006). Cd-hit: a fast program for clustering and comparing large sets of protein or nucleotide sequences. Bioinformatics 22: 1658-1659.

LIU, M.M., DAVEY, J.W., BANERJEE, R., HAN, J., YANG, F., ABOOBAKER, A. BLAXTER, M.L. and DAVISON, A. (2013). Fine mapping of the pond snail left-right asymmetry (chirality) locus using RAD-Seq and Fibre-FISH. PLoS One 8: e71067.

MEYEROWITZ, E.M. (2002). Comparative genomics - Plants compared to animals: The broadest comparative study of development. Science 295: 1482-1485.

MORRILL, J.B. (1982). Developmental Biology of the Pulmonate Gastropod, Lymnaea. In Developmental Biology of Freshwater Invertebrates, (ed. HARRISON, F. W.). Alan R. Liss, Inc., New York, pp.399-483.

PETERSON, K.J., COTTON, J.A., GEHLING, J.G. and PISANI, D. (2008). The Ediacaran emergence of bilaterians: congruence between the genetic and the geological fossil records. Philosophical Transactions Of The Royal Society BBiological Sciences 363: 1435-1443.

QUINT, M., DROST, H.-G., GABEL, A., ULLRICH, K.K., BOENN, M. and GROSSE, I. (2012). A transcriptomic hourglass in plant embryogenesis. Nature 490: 98-101.

RAVEN, C.P. (1966). Morphogenesis: the analysis of molluscan development. Pergamon Press.

SCHIER, A.F. (2007). The maternal-zygotic transition: death and birth of RNAs. Science 316: 406-407.

SCHILTHUIZEN, M. and DAVISON, A. (2005). The convoluted evolution of snail chirality. Naturwissenschaften 92: 504-515.

SHEN-ORR, S.S., PILPEL, Y. and HUNTER, C.P. (2010). Composition and regulation of maternal and zygotic transcriptomes reflects species-specific reproductive mode. Genome Biology 11.

STITZEL, M.L. and SEYDOUX, G. (2007). Regulation of the oocyte-to-zygote transition. Science 316: 407-408.

STURTEVANT, A.H. (1923). Inheritance of direction of coiling in Limnaea. Science 58: 269-270.

TADROS, W. and LIPSHITZ, H.D. (2009). The maternal-to-zygotic transition: a play in two acts. Development 136: 3033-3042.

WANG, J., GARREY, J. and DAVIS, RICHARD E. (2013). Transcription in pronucle and one- to four-cell embryos drives early development in a nematode. Current Biology 10.1016/j.cub.2013.11.045.

WIESCHAUS, E. (1996). Embryonic transcription and the control of developmental pathways. Genetics 142: 5-10. 


\section{Further Related Reading, published previously in the Int. J. Dev. Biol.}

Maternal RNAs encoding transcription factors for germline-specific gene expression in Drosophila embryos Jun Yatsu, Makoto Hayashi, Masanori Mukai, Kayo Arita, Shuji Shigenobu and Satoru Kobayashi Int. J. Dev. Biol. (2008) 52: 913-923

http://www.intjdevbiol.com/web/paper/082576jy

Centroid, a novel putative DEAD-box RNA helicase maternal mRNA, is localized in the mitochondrial cloud in Xenopus laevis oocytes Malgorzata Kloc and Agnes P. Chan

Int. J. Dev. Biol. (2007) 51: 701-706

http://www.intjdevbiol.com/web/paper/072293mk

Differences in maternal supply and early development of closely related nematode species

Magdalena Laugsch and Einhard Schierenberg

Int. J. Dev. Biol. (2004) 48: 655-662

http://www.intjdevbiol.com/web/paper/031758ml

Identification and characterization of maternally expressed genes with mRNAs that are segregated with the endoplasm of early ascidian embryos

$\mathrm{K}$ Imai, N Satoh and Y Satou

Int. J. Dev. Biol. (1999) 43: 125-133

http://www.intjdevbiol.com/web/paper/10235388

HrWnt-5: a maternally expressed ascidian Wnt gene with posterior localization in early embryos

Y Sasakura, M Ogasawara and K W Makabe

Int. J. Dev. Biol. (1998) 42: 573-579

http://www.intjdevbiol.com/web/paper/9694628

5 yr ISI Impact Factor $(2011)=2.959$

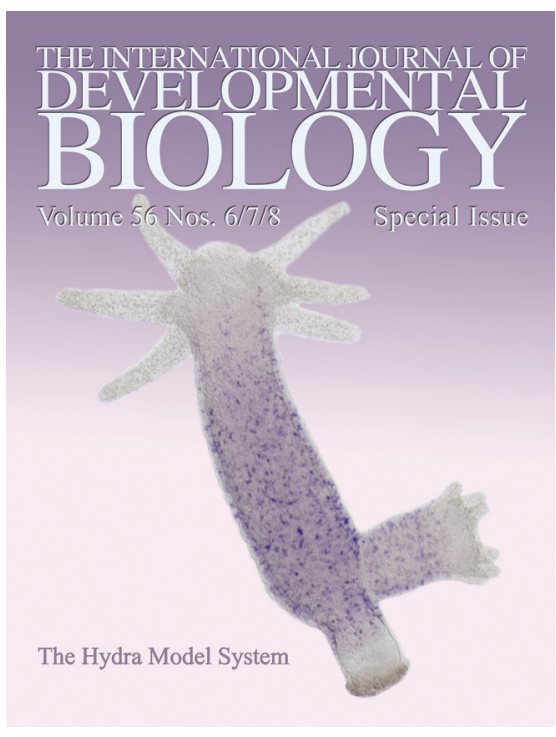

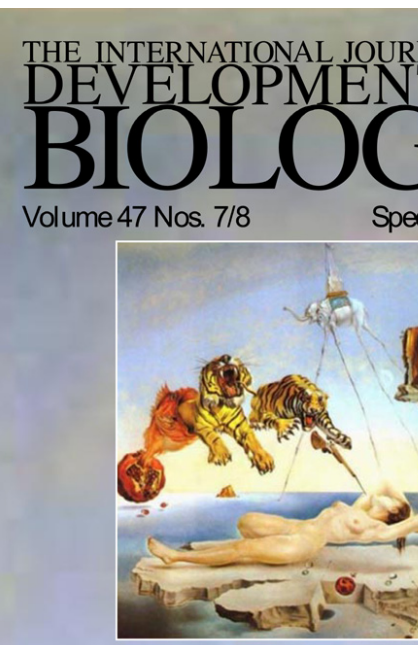

Evolution \& Development
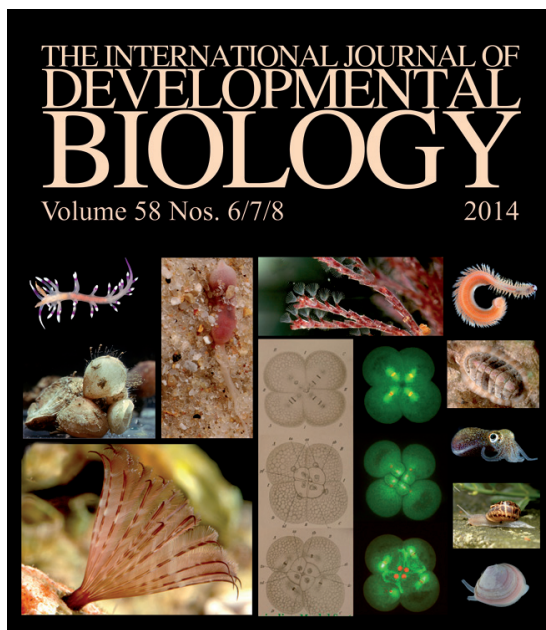

Spiralian Model Systems
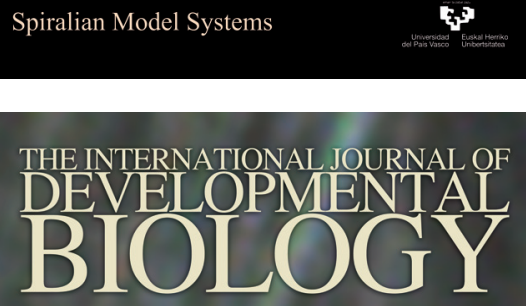

Volume 56 Nos. 1/2/3

Special Issue

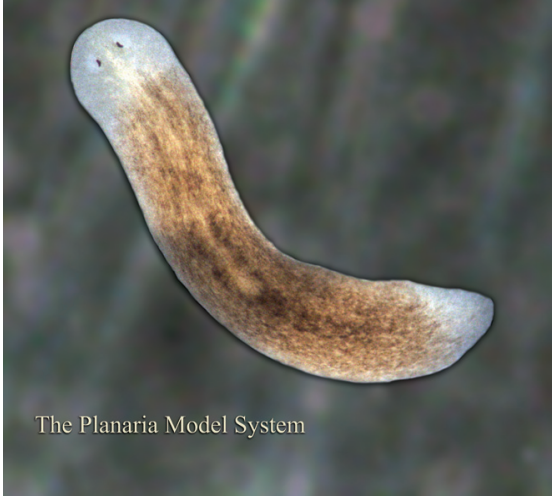

